\title{
ARCILLAS IDENTIFICADAS EN SUELOS DE COSTA RICA A NIVEL GENERALIZADO DURANTE EL PERÍODO 1931-2014: II. MINERALOGÍA DE ARCILLAS EN SUELOS CON CARACTERÍSTICAS VÉRTICAS Y OXÍDICO CAOLINÍTICAS
}

\author{
Alfredo Alvarado ${ }^{1 / *}$, Rafael Mata*, Miguel Chinchilla ${ }^{* *}$
}

Palabras clave: Arcilla, suelo, Vertisol, Alfisol, Ultisol, Oxisol, amorfos, alófanas, illita, halloysita, metahalloysita, imogolita, ferrihidrita, hematita, maghemita, magnetita, goethita, gibbsita, caolinita, esmectita, Costa Rica, trópico.

Keywords: Clay, soil, Vertisol, Alfisol, Ultisol, Oxisol, smectite, montmorrillonite, vermiculite, illite, halloysite, metahalloysite, chlorite, ferrihydrite, hematite, maghemite, magnetite, goethite, kaolinite, gibbsite, Costa Rica, tropic.

Recibido: 04/06/13

\section{RESUMEN}

Se resume la información disponible sobre la mineralogía de arcilla de los horizontes superficiales del suelo, aunque se menciona la mineralogía de los horizontes B cuando esta es diferente a la de los horizontes A, de manera relevante, en suelos de Costa Rica desde 1931 hasta el presente. Se enfatiza en la información disponible para (1) esmectíticas y de arcillas interestratificadas en Vertisoles y otros suelos con características vérticas y (2) óxidos-hidróxidosoxihidróxidos-caolinita-gibbsita en Alfisoles, Ultisoles y Oxisoles. En el texto se discute la génesis (procesos de formación) de estos grupos dominantes de arcilla cuando se dispone de suficiente información.

1 Autor para correspondencia. Correo electrónico: alfredo.alvarado@ucr.ac.cr

Centro de Investigaciones Agronómicas. Universidad de Costa Rica. San José, Costa Rica.
Aceptado: 16/10/13

\begin{abstract}
Clay minerals identified in soils of Costa Rica from 1931 to 2014: II. Major clay types described in soils with vertic, and oxidickaolinic properties. This paper summarizes available information on soil clay mineralogy in topsoils of Costa Rica, including clay minerals described in B horizons when significantly different from predominant mineralogy in the topsoil. The soil clay suites ("predominant clay groups") emphasized are grouped as: (1) smectites and interstratified clays (Vertisols and other soils with vertic properties), and (2) oxides-hidroxidesoxihidroxides-kaolinite-gibbsite (in Alfisols, Ultisols and Oxisols). The soil clay genesis of these dominant groups is discussed when enough information is available.
\end{abstract}

\footnotetext{
** Instituto Costarricense de Electricidad. San José, Costa Rica.
} 


\section{INTRODUCCIÓN}

El estudio de la mineralogía de arcillas en suelos de Costa Rica se inicia con Anderson y Byers (1931) y continúa hasta el presente de una manera más acelerada y con herramientas cada vez más especializadas. En el artículo de Alvarado et ál. (2014a) se discuten los aspectos históricos, metodológicos y de formación de minerales de arcilla en suelos de Costa Rica, con énfasis en la meteorización y formación de arcillas en suelos derivados de cenizas volcánicas. En el presente trabajo, se enfatiza en la mineralogía de arcillas del suelo tipos esmectita y kandita asociadas a óxidos e hidróxidos de $\mathrm{Fe}$ y Al.

En general, aparte de las arcillas formadas en Andisoles y suelos con características ándicas discutidas por Alvarado et ál. (2014a), las esmectitas y kanditas asociadas a óxidos e hidróxidos de $\mathrm{Fe}$ y $\mathrm{Al}$ representan los productos finales de la formación de arcillas en los suelos del país, las primeras en los ecosistemas ústicos estacionalmente secos y las últimas en los ecosistemas údico-perúdico de pisos altitudinales isotérmicos e isohipertérmicos. A continuación se describe la distribución, la génesis y las principales propiedades de estos tipos de arcilla dominante, es decir aquellas mencionadas por los investigadores como más abundantes en el horizonte superficial y en algunos casos en todo el perfil del suelo.

\section{VERTISOLES Y OTROS SUELOS CON ESMECTITAS Y ARCILLAS INTERESTRATIFICADAS}

Vertisoles: Son suelos oscuros y arcillosos de mineralogía esmectítica dominante con grietas que se abren y cierran periódicamente, en su mayoría con características de neutras a básicas (Wilding y Puentes 1988, Ahn y Elliot 1989). En Costa Rica también se los reconocen como "sonsocuitles", que ocupan un área aproximada de $621 \mathrm{~km}^{2}$ y asociados con Mollisoles de mineralogía halloysítica en las zonas de relieve plano o depresional del Pacífico Seco (Vásquez 1978a,b, Mata1982, Mata et ál. 1996, Winters 1997) y del Valle Central Occidental (Vargas y Torres 1958, Motavalli et ál. 1995). En Guanacaste se las encuentra normalmente en los sectores medio, o de valle fluvial, o en el sector de la llanura aluvial en la parte distal de los desbordamientos los ríos Tempisque, Bebedero, Cañas y Uruca en microrelieves de gilgai.

Por su similitud en comportamiento, otros suelos con propiedades vérticas se incluyen en la presente discusión. Son suelos que se clasifican por sus características dominantes en otros órdenes, pero presentan en algún grado de características relacionadas con esmectitas, particularmente en superficie. En general, los Vertisoles de Costa Rica tienen más de un $50 \%$ de la fracción arcillosa dominada por esmectitas y se forman a partir de tobas riolíticas con adiciones de ceniza volcánica andesítica muy fina en el Valle Central y en Guanacaste, en áreas con una estacionalidad climática muy definida. Debido a cambios climáticos y tectónicos importantes, las condiciones lacustres geomorfológicamente efímeras por efecto de colmatación en el Valle Central se han modificado, por lo que los Vertisoles pueden ocupar hoy en día algunas posiciones no necesariamente depresionales.

En Costa Rica los principales Vertisoles se clasifican como Usterts (estacionalmente secos), Uderts y Aquerts (los más húmedos), encontrándose sobre las mesetas tobáceas e ignimbríticas de la formación Bagaces en el paisaje plano del Guanacaste y en los lentes coluvio-aluviales del Valle Central. En la Figura 1 se nota que los Vertisoles dominantes en Guanacaste se alinean en una zona de basín durante los períodos Paleoceno-Eoceno al margen izquierdo del actual cauce del río Tempisque, lo que podría explicarse en función de fallamiento o del cauce anterior del mismo río cuando drenaba hacia el noroeste, como menciona (Dengo 1962). 


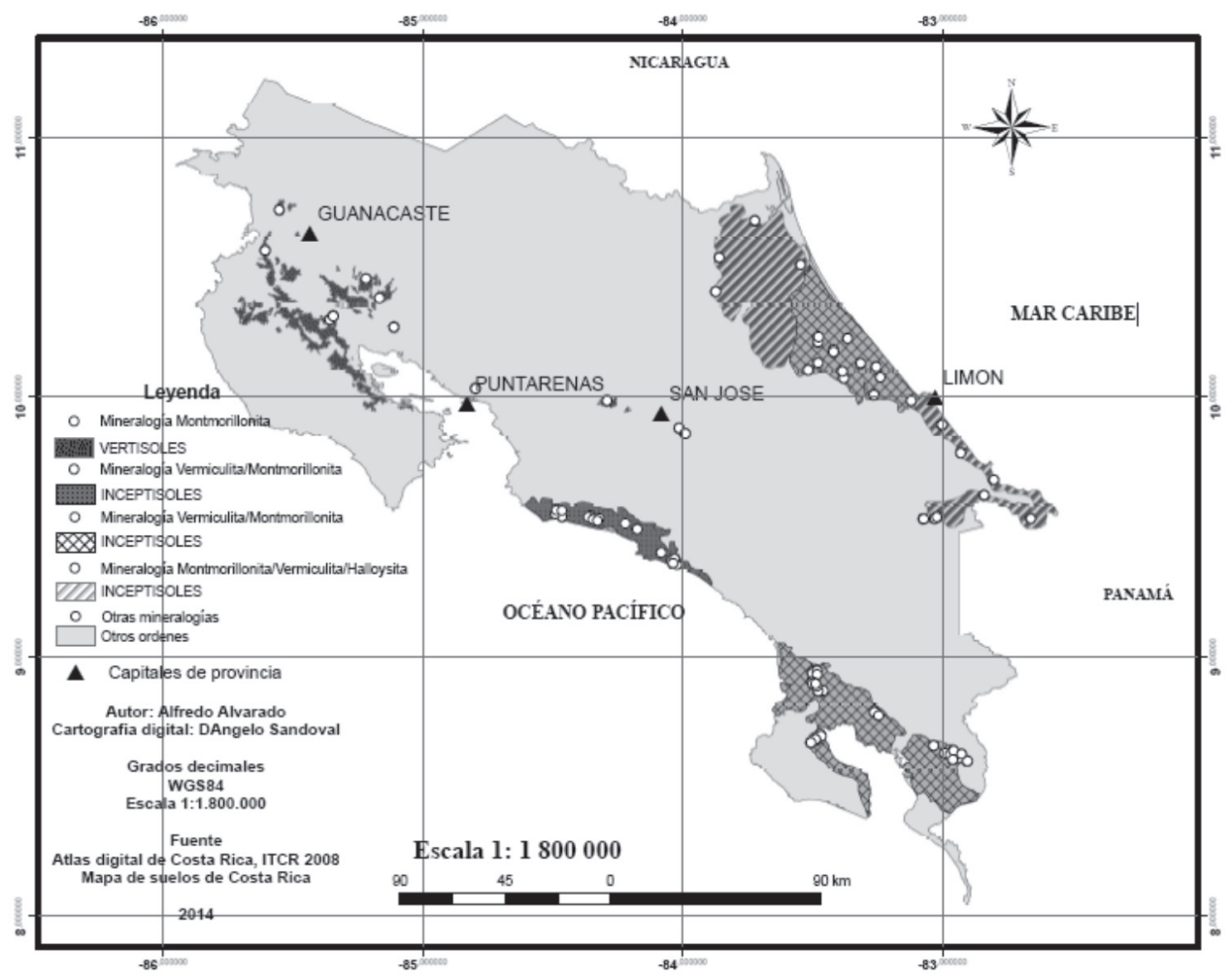

Fig. 1. Distribución de suelos con mineralogía esmectítica en Costa Rica.

Para que se origine este tipo de suelo es necesaria la confluencia de ciertos factores, lo que normalmente ocurre en condiciones aluviales y fluvio-lacustres: (1) una zona depresional que impida el buen drenaje, (2) acumulación de materiales ricos en $\mathrm{Si}, \mathrm{Ca}$ y $\mathrm{Mg}$ y (3) que éstos sean de tamaño coloidal. Estas condiciones propician la formación de arcillas 2:1 del tipo esmectítico que por sus reacciones de contracción y expansión de acuerdo con su contenido de humedad, imprimen características muy particulares a estos suelos y que afectan tanto las labores agrícolas como la instalación y mantenimiento de las obras de ingeniería. En su condición natural la mayoría de estos suelos no presentan condiciones redoximórficas, mientras que los irrigados por varios años consecutivos pueden pertenecer al subgrupo Aquic (p.e.
Epiaquerts) cuando se mantienen saturados por períodos prolongados revelándose en ellos condiciones de oxi-reducción y cambios en su potencial agrícola. En la parte norte de Guanacaste, cerca de la frontera con Nicaragua se encuentran Vertisoles ácidos probablemente elevados a su posición actual posteriormente a su formación (Mata et ál. 1996), los cuales presentan una concentración elevada de aluminio intercambiable y clasifican como Alic y Alic Aquic Dystruderts.

\section{Suelos con características vérticas en el}

Caribe: Además de los Vertisoles, muchos suelos presentan características relacionadas con esmectitas en los valles coluvio-aluviales de ambas costas del país. En el Caribe, Arias et ál. (2010b) resumen lo existente en la literatura y también 
documentan la dominancia de (1) montmorillonita asociada con vermiculita y metahalloysita y de (2) montmorillonita asociada con metahalloysita en la zona sureste de la costa, y que la arcilla es probablemente heredada de la formación geológica Uscari, rica en bentonitas (Mathers et ál. 1991) presente en la circundante cordillera de Talamanca. Arias et ál. (2010b) evidencian que en la región noroeste de la costa dominan (1) la metahalloysita asociada con montmorillonita y trazas de illita, (2) la metahalloysita asociada con gibbsita y montmorillonita y (3) la metahalloysita asociada con gibbsita, neoformadas in situ a partir de la mineralización de cenizas volcánicas retrabajadas y depositadas de manera aluvial (Figura 2).

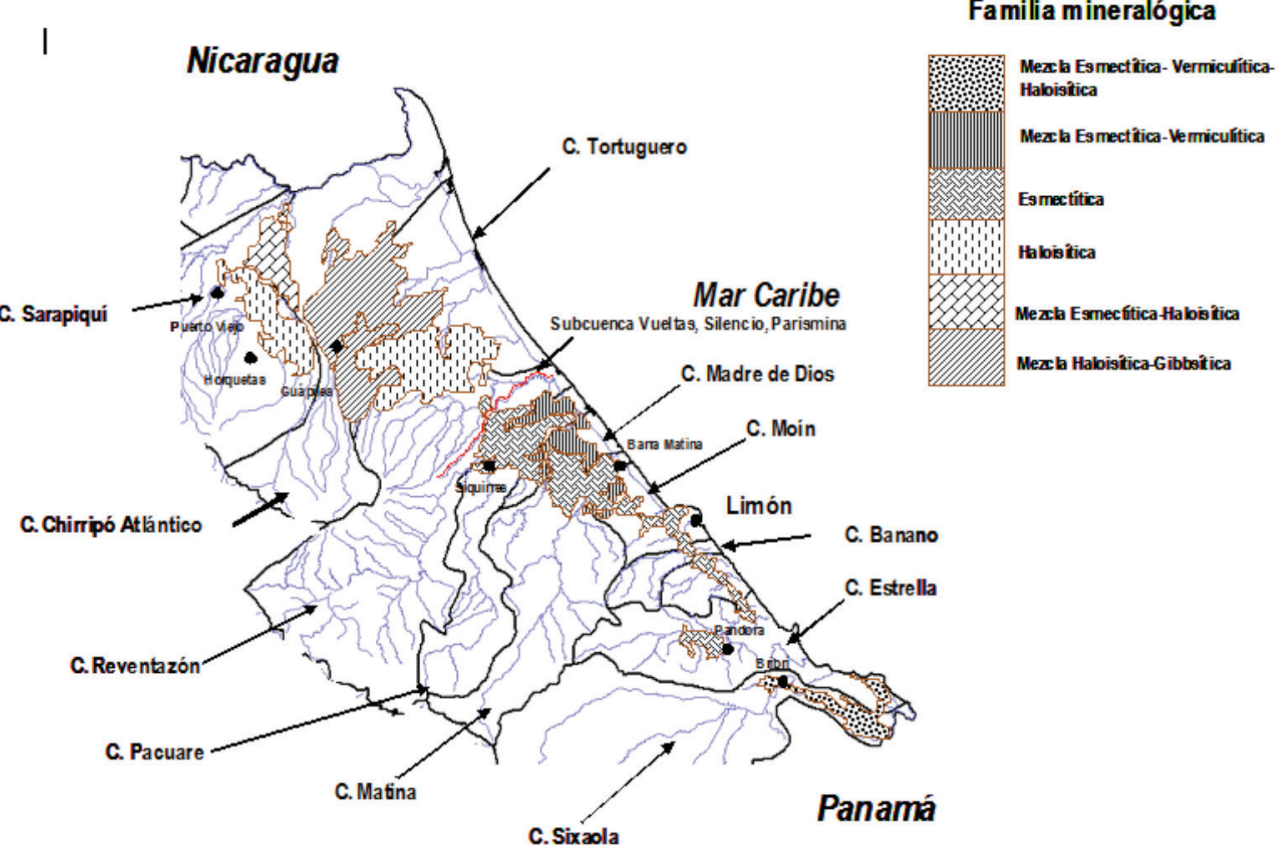

Fig. 2. Distribución preliminar de familias mineralógicas en suelos de las llanuras aluviales del Caribe de Costa Rica (tomado de Arias et ál. 2010b).

La presencia de depósitos relacionados con cenizas volcánicas en el Caribe también se asocia a la actividad del complejo o gran campo volcánico del Irazú-Turrialba, al vulcanismo de actividad tardía en la cordillera de Talamanca durante el Plio-Pliestoceno y a la actividad de campo volcánico del volcán Barú. La evolución geológico-geomorfológica de esas formaciones ha formado parte de esa orogénesis volcánica en distintos períodos y en los suelos formados en las laderas como en el piedemonte se encuentran con frecuencia lentes de cenizas, aún sin gran evolución pedogenética.

Suelos con características vérticas en el Pacífico: Ortiz y Collins (1992) documentan que en los suelos aluviales con drenaje moderado del Pacífico Central del país, en los valles de Parrita-Quepos-Dominical, domina la mineralogía vermiculita hidroxi-interestratificada (HIV) asociada con montmorillonita (Cuadro 1); sin embargo, estos suelos no presentan la mayoría 
Cuadro 1. Principales mineralogías de arcilla identificadas en suelos aluviales del Pacífico Central y Sur de Costa Rica (adaptado de Ortiz y Collins 1992).

\begin{tabular}{llll}
\hline \multicolumn{1}{c}{ Sitio } & \multicolumn{1}{c}{ Tipo de suelo } & \multicolumn{2}{c}{ Mineralogía } \\
& & \multicolumn{1}{c}{ Dominante } & \multicolumn{1}{c}{ Secundaria } \\
\hline Quepos $(\mathrm{n}=2)$ & Fluventic Eutrudepts & Verm.Interestr.-Mont. & Cuarzo-Caol.-Gibb. \\
Quepos $(\mathrm{n}=2)$ & Fluventic Eutrudepts & Verm.Interestr. & Mont.-Cuarzo-Caol.-Gibb. \\
Coto $(\mathrm{n}=2)$ & Aquic Eutrudepts & Mont.-Verm & Caol-Cuarzo \\
Coto $(\mathrm{n}=2)$ & Typic Eutrudepts & Mont.-Verm & Cuarzo-Caol.-Gibb. \\
Coto $(\mathrm{n}=3)$ & Aeric Endoaquepts & Mont. & Verm.-Cuarzo-Caol. \\
Coto $(\mathrm{n}=2)$ & Typic Epiaquepts & Mont.-Verm & Cuarzo-Caol. \\
\hline
\end{tabular}

de las propiedades comunes de los suelos con características vérticas (p.e. resquebrajamiento, etc.). Se considera que estas arcillas probablemente sean provenientes de lutitas calcáreas identificadas en los márgenes de las cuenca de los ríos de la zona y dominadas en su fracción arcilla por montmorillonita cálcica medianamente expansible, asociada a las cloritas descritas por (Sánchez 1994). Sin embargo, al estudiar los suelos de esa misma zona, derivados de sedimentos de rocas ígneas extrusivas (basalto y andesita) de los bloques tectónicos de Esterillos y Parrita, Fisher y Ryan (2006) mencionan que en la llanura aluvial y terrazas más jóvenes (5000 a 10000 años) predomina la beidelita con algo de caolinita "desordenada". En el Pacífico Sur, en los suelos mal drenados de los valles del Diquís y Coto (Ortiz y Collins 1992) y en los valles sobre terrazas marinas (Holdridge et ál. 1971) mencionan que domina la montmorillonita con vermiculita hidroxi-interestratificada; esta arcilla es posiblemente heredada de los suelos erosionados y formados a partir de tufitas siliciclásticas verdosas de grano fino en las que la presencia de esmectita indica la existencia de una importante pero variable cantidad de material volcanoclástico descrito en los alrededores de esta región (Scheucher et ál. 2008). Los mismos autores consideran que esas arcillas se forman en una secuencia esmectita-illita-esmectita (interestratificada) y en menor proporción zeolita transformada diagenéticamente a partir de otras formaciones geológicas de la misma región.

\section{Suelos con características vérticas en el} Valle Central: Varios autores (Motavalli et ál. 1995, Soto 1998, USDA-SCS 2012) mencionan la presencia de esmectitas en suelos del Valle Central (p.e. Lindora, Coris y La Chinchilla). Motavalli et ál. (1995) relacionan el comportamiento de la mineralización de $\mathrm{N}$ en suelos con este tipo de mineralogía, mientras que Soto (1998) relaciona esta característica con la retención de fosfatos. El trabajo del USDA-SCS (2012) menciona la ocurrencia de esmectitas en suelos clasificados como finos, caoliníticos, isotérmicos, Vertic Paleustalfs, formados sobre un cono de deyección recubierto con capas de lahares (masas caóticas de cenizas, arcillas, bloques de lavas y pómez) y cenizas.

\section{PRINCIPALES TIPOS DE ARCILLAS ESMECTÍTICAS E INTER- ESTRATIFICADAS}

\section{Definición, características y procesos de for- mación de la metahalloysita}

La metahalloysita (7 $\AA$ ) es una arcilla dioctaédrica común en climas húmedos y tropicales (Mizota y van Reeuwijh 1989, Quantin et ál. 1991). Se forma a partir de plagioclasas intermedias a 
sódicas que se transforman a halloysita y luego a metahalloysita en un ambiente ligeramente ácido a neutro y en presencia de humedad relativamente alta (Besoain 1985) o bien por efecto de actividad hidrotermal (Sudo y Shimoda 1978). La metahalloysita se puede identificar mediante el análisis de patrones de difracción de rayos $\mathrm{X}$ (DRX) por sus espaciamientos basales de reflejos amplios, irregulares y débiles entre 7,20 $\AA$ y $7,50 \AA$ (Figura 3 ) que indican que son desordenadas y poseen pequeños cristales y capas interestratificadas con diferentes estados de hidratación (Brown y Brindley 1980, Joussein et ál. 2005). La metahalloysita tiene una densidad alrededor de 2,6 g.ml-1 y una CIC entre 8 a 15 $\operatorname{cmol}(+) \cdot 1^{-1}$ arcilla.

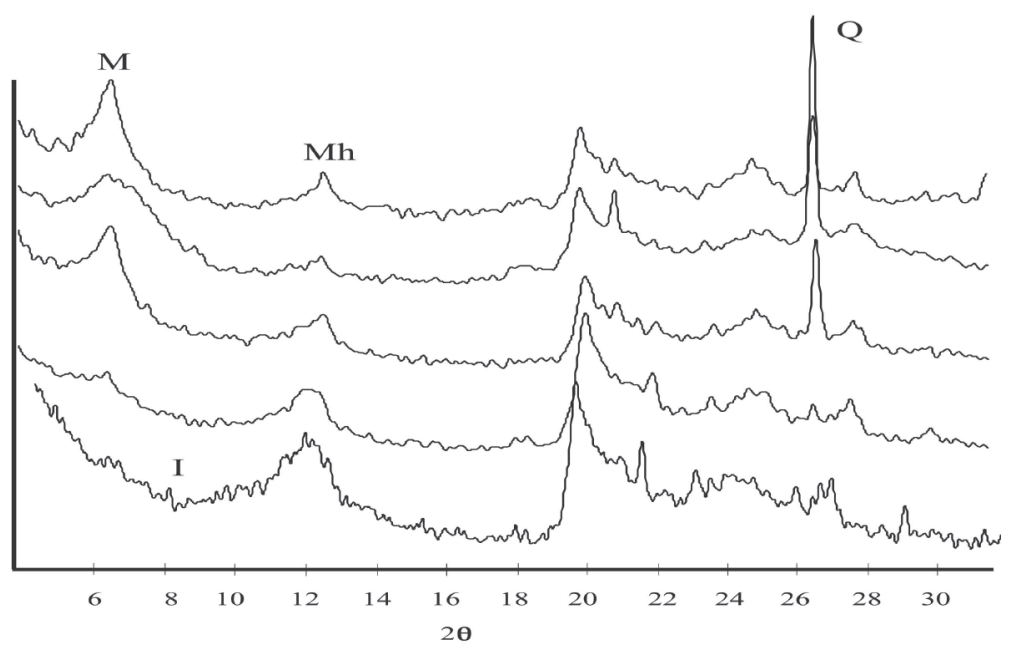

Fig. 3. Difractogramas de arcilla en 5 suelos en los que se identifican metahalloysita (Mh) con diferentes grados de cristalinidad, illita (I), montmorillonita (M) y cuarzo (Q) (tomado de Arias et ál. 2010b).

En la región noroeste del Caribe de Costa Rica, Arias et ál. (2010b) encontraron cantidades variables de metahalloysita según la profundidad del horizonte muestreado para análisis. Por la poca presencia de alófana en los suelos aluviales de las llanuras del Caribe varios autores sugieren que la meteorización directa de feldespatos intermedios a halloysita, provenientes de las cenizas volcánicas depositadas en forma coluvio-aluvial, conlleva a la formación de metahalloysita en las zonas bajas de la costa (Arias et ál. 2010b, Joussein et ál. 2005, Nieuwenhuyse 1996). Otros autores sugieren que la metahalloysita es heredada, formada por transformación de plagioclasas debido a la acción hidrotermal en los suelos de las laderas volcánicas aledañas de la cordillera
Volcánica Central y posteriormente depositada como producto de la erosión de estos suelos (Jongmans et ál. 1994, Nieuwenhuyse y van Breemen 1997). Kautz y Ryan (2003) explican la presencia de metahalloysita y gibbsita en el sector de Sarapiquí como resultado de la transformación de halloysita (10 ̊̊) a metahalloysita (7 ̊̊), lo que podría explicar la coexistencia de halloysita y gibbsita en la parte aluvial de las cuencas de los ríos Colorado y Sarapiquí encontrada por Holdridge et ál. (1971).

\section{Definición, características y procesos de formación de la illita}

La illita es una arcilla 2:1 no expandible de unidades cristalinas unidas entre sí por iones 
de $\mathrm{K}^{+}$lo que las mantiene estrechamente unidas sin sufrir procesos de expansión-contracción ante cambios de humedad. La illita está estructurada por una lámina de octaedros de $\mathrm{Al}$ en medio de 2 capas de tetraedros de $\mathrm{Si}$ en donde los vértices apuntan en una misma dirección. Los átomos de $\mathrm{Si}^{4+}$ están reemplazados por $\mathrm{Al}^{3+}$ y la diferencia de carga es balanceada con $\mathrm{K}^{+}$. Cuando la carga no es balanceada con $\mathrm{K}^{+}$se pueden adsorber o intercambiar otros cationes.

De acuerdo con Besoain (1985), la illita es un mineral poco común en suelos aluviales tropicales, debido a que se degradan a minerales no micáceos y escasamente se presentan en suelos derivados de materiales volcánicos pero son comunes en suelos ricos en micas. El análisis de DRX permite identificar la illita a reflejos basales planos (001) en alrededor de $10 \AA$ y por las características de intensidad de los picos en muestras con este tipo de arcilla se puede deducir su abundancia relativa. En Costa Rica los suelos que contienen este mineral se encuentran principalmente en la cuenca del río Chirripó (Arias et ál. 2010b), aunque Cortés (1981) también la menciona en sedimentos sobre corales y en sedimentos en suspensión en la cuenca del río La Estrella.

\section{Definición, características y procesos de formación de la montmorillonita}

De acuerdo con Porta et ál. (1994), este tipo de arcilla es la más representativa del grupo de las esmectitas en cuanto a su capacidad de expansión y retracción interlaminar por el humedecimiento y secado, debido a que su estructura posibilita la hidratación de los cationes interlaminares que provocan la separación de las láminas (Figura 4). La montmorillonita consiste en 2 láminas de tetraedros de $\mathrm{Si}$ y una lámina de octaedros de $\mathrm{Al}$ en el que se genera carga eléctrica por sustitución isomórfica del $\mathrm{Al}^{3+}$ por $\mathrm{Mg}^{2+}$. La carga de la montmorillonita es esencialmente permanente y derivada de la sustitución isomórfica y por la de-protonación de los $\mathrm{OH}$ de los bordes, lo cual genera una pequeña parte de la carga que es dependiente del $\mathrm{pH}$ y se originan por procesos de hidrólisis de plagioclasas intermedias a sódicas de rocas volcánicas, o bien por actividad hidrotermal en zonas volcanogénicas (Besoain 1985). La capacidad de intercambio catiónico de las esmectitas es alta, alrededor de 80 y $120 \mathrm{cmol}(+) .1^{-1}$, la superficie específica interna y externa es muy elevada 600 y $800 \mathrm{~m}^{2} \mathrm{~g}^{-1}$, es decir $15-20$ veces mayor que las arcillas de estructura 1:1.

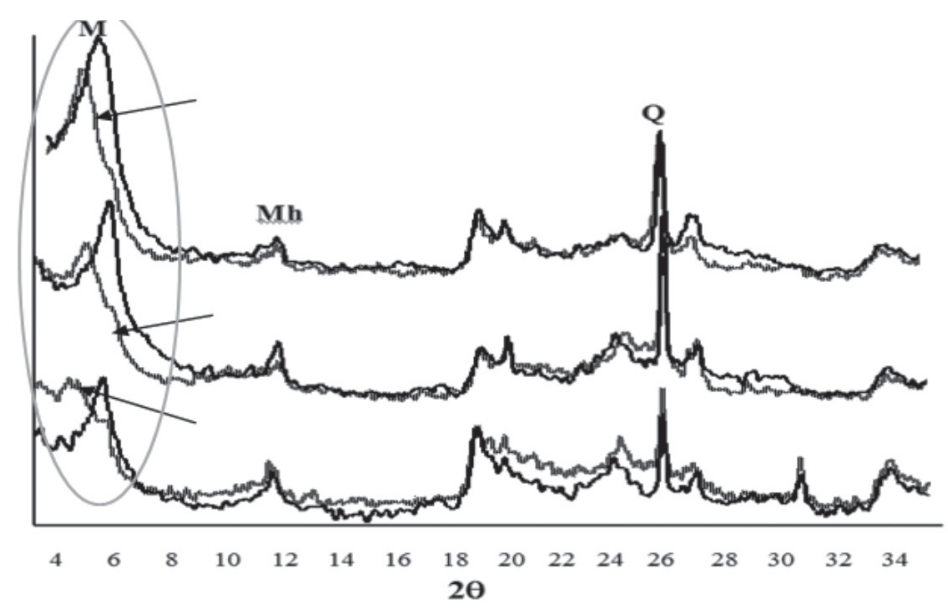

Fig. 4. Difractogramas de muestras glicoladas de 3 suelos en los que se identifican montmorillonita (M) con grados variables de cristalinidad, metahalloysita (Mh) y cuarzo (Q) (tomado de Arias et ál. 2010b). 
La presencia de montmorillonita en Costa Rica se ha reportado en varias ocasiones en los suelos del Caribe sureste de Costa Rica (Drosdoff y Pearson 1951, López 1963, Stotzky y Martín et ál. 1963, Krezdorn et ál. 1967, Cortés 1981, Nieuwenhuyse 1996, Mora 2007, Arias 2010b), del Caribe noroeste (Holdridge et ál. 1971, Nieuwenhuyse et ál. 1994, Nieuwenhuyse 1996, Kautz y Ryan 2003, Arias et ál. 2010b), del Pacífico norte (Winters 1997, USDA-SCS 2012), del Pacífico Central y Sur (Stotzky y Martín 1963, Holdridge et ál. 1971, Ortiz y Collins 1992, Sánchez 1994) y del Valle Central (López 1963, Motavalli et ál. 1995), siempre en suelos de origen lacustre o aluvial. Winters (1997) considera que en todos los suelos formados a partir de ignimbritas en Guanacaste, la montmorillonita es producto de neoformación, sea heredada, derivada de procesos hidrotermales ocurridos durante la deposición de los materiales o formada por el proceso de meteorización; en este último caso su contenido y el de $\mathrm{Ca}$ aumentan con la profundidad del suelo. Esto último también ocurre en los Vertisoles del valle de Santa Ana, valle Central Occidental, donde se pueden encontrar concreciones de carbonato de calcio de más $5 \mathrm{~cm}$ de diámetro en el subsuelo.

La montmorillonita también ha sido reportada por algunos autores (Bertolani y Loschi 1986, Berrangé et ál. 1990, Mathers et ál. 1991) en varios depósitos de bentonita con bajo contenido de este tipo de material coloidal pero de alto contenido de montmorillonita formada por meteorización in situ, alteración hidrotermal o diagénesis de productos como el vidrio y cenizas volcánicas con alto contenido de plagioclasas. Estos depósitos de origen lacustre (montmorillonita sódica) han sido encontrados en Loma Camastro (noreste de Liberia), mientras que otros de origen sedimentario marino (montmorillonita cálcica) han sido reportados en las formaciones geológicas Senosri, Uscari y Punta Judas. Al analizar muestras de lutitas calcáreas en una capa del Complejo de Nicoya, en las márgenes de la cuenca del río Paquita, Sánchez (1994) menciona la presencia de montmorillonita cálcica asociada a clorita de origen lacustre, depositadas en un ambiente de aguas tranquilas, de baja energía y en posición semi-horizontal, con la recurrencia de colmatación en ambientes de estancación evidenciada por la presencia de materia orgánica de tipo vegetal típicos de turbiditas.

La presencia de cantidades importantes de montmorillonita en sedimentos marinos depositados frente a la península de Nicoya, sugiere que este tipo de arcilla es un detrito formado bajo condiciones terrestres desde hace mucho tiempo, en lugar de ser el producto de alteraciones autigénicas de ceniza volcánica (Spinelli y Underwood 2004). Sin embargo, otros autores que han trabajado con los mismos sedimentos (Rochelle et ál. 1989, Gaudin et ál. 2005, Charpantier et ál. 2011) describen como posible mecanismo de formación de la montmorillonita rica en $\mathrm{Fe}$, la disolución de pirita con enriquecimiento simultáneo con $\mathrm{Si}, \mathrm{O}$, $\mathrm{Mg}, \mathrm{K}$, Na y Ca bajo condiciones marinas.

En el sureste de la región Caribe la montmorillonita es el mineral arcilloso más abundante en todos los horizontes de los suelos, asociada a minerales primarios como cuarzo y en menor medida a plagioclasas e incluso a óxidos de hierro tipo ferrihidrita, magnetita y goethita (Arias et ál. 2010b). En los suelos de esta zona, la montmorillonita se encontró siempre mezclada con metahalloysita y en algunos casos con vermiculita principalmente en las cuencas de los ríos Estrella, Banano, Madre de Dios y Pacuare. La presencia de arcillas 2:1 expandibles en suelos del Caribe sureste de Costa Rica también ha sido documentada por varios autores (Drosdoff y Pearson 1951, López 1963, Stotzky y Martín 1963, Krezdorn et ál. 1967, Nieuwenhuyse 1996), en sedimentos sobre arrecifes de coral en Cahuita (Cortés 1981) y en calizas cársticas en los alrededores de la ciudad de Limón (Mora 2007). Jongmans et ál. (1994) indican que los procesos hidrotermales en rocas andesíticas de la cordillera Central son los posibles responsables de la transformación de parte de los minerales primarios a filosilicatos 2:1, los cuales forman depósitos bentónicos que una vez erosionados de las zonas altas de la cordillera de Talamanca pasan a formar parte 
de los suelos en la planicie aluvial por herencia (Mathers et ál. 1991).

\section{Definición, características y procesos de formación de la beidelita}

La beidelita es un mineral dioctahédrico expandible de composición variable que se sitúa entre la montmorillonita y la vermiculita, relativamente frecuente en suelos. Se origina por meteorización en ambiente básico de rocas volcánicas básicas y cenizas volcánicas y es frecuente en bentonitas. La beidelita se diferencia de la montmorillonita por difracción de rayos $\mathrm{X}$ al tratarla con sales de litio, ya que la montmorillonita-Li pierde sus propiedades expansibles con moléculas polares al calentarla a $250^{\circ} \mathrm{C}$ por unas horas, de manera que su estructura colapsa a un espaciado de 9,5 a $9,8 \AA$, mientras que la beidelita tratada de la misma forma se expande a $17,5 \AA$ (Besoain 1985).

Fisher y Ryan (2006) al estudiar los suelos derivados de sedimentos de rocas ígneas extrusivas (basalto y andesita) de los bloques tectónicos de Esterillos y Parrita, mencionan que en la llanura aluvial y en las terrazas más jóvenes (5000 a 10000 años) predomina la beidelita con algo de caolinita "desordenada", mientras que en las terrazas más antiguas (37 000 a 127000 años) predomina la caolinita "desordenada" con trazas de esmectita; una situación similar ocurre al comparar la composición mineralógica de los horizontes de suelo más profundos que los horizontes B más superficiales. La composición de la matriz de los suelos de $<10000$ años consiste de beidelita-plagioclasa-augita-cuarzo-magnetita, mientras que en suelos de $>37000$ años consiste de caolinita "desordenada"-goethita-hematitacuarzo-magnetita. Fisher y Ryan (2006) consideran que la caolinita "desordenada" es producto de la meteorización de la beidelita sin que ocurra el paso intermedio de formación de esmectitas interestratificadas, debido al régimen de humedad ústico predominante en esta región; si por el contrario no ocurriese un período seco prolongado, la tendencia sería de formar arcillas interestratificadas como ocurre en el área de los
Cotos y Golfito (Stotzky y Martín 1963, Ortiz y Collins 1992).

Laguna (1985) al estudiar la fracción arcilla de andesitas, latiandesitas y tufitas no diferenciadas describe la formación del mineral de arcilla irterestratificado illita/beidelita por acción hidrotermal continuada sobre la ya formada beidelita, semejante a otros materiales conocidos como "intergrados cloríticos". Otros minerales como illita, pirofillita y metahalloysita se encuentran en muy poca proporción.

\section{Definición, características y procesos de formación de la vermiculita}

La estructura de la vermiculita se asemeja a la de las micas, de las cuales puede formarse por meteorización, en las que la carga negativa se debe a sustituciones de $\mathrm{Si}^{4+}$ por $\mathrm{Al}^{3+}$ en la capa tetraédrica en una proporción del orden de 0,6 a 0,9 celdilla unidad; esta carga se ve neutralizada en parte por la carga positiva neta generada por las sustituciones en las capas octaédricas de $\mathrm{Fe}^{3+}$ por $\mathrm{Mg}^{2+}$ y por la fijación interlaminar de $\mathrm{K}^{+} \mathrm{y}$ $\mathrm{NH}_{4}{ }^{+}$(Porta et ál. 1994, Schaetzl y Anderson 2005). La CIC de las vermiculitas varía entre 100 y $150 \mathrm{cmol}(+) . \mathrm{l}^{-1}$ y tiene capacidad de retener $\mathrm{K}^{+}$ y $\mathrm{NH}_{4}^{+}$, con una superficie específica que oscila entre 600 y $800 \mathrm{~m}^{2} \mathrm{~g}^{-1}$ (Porta et ál. 1994). La vermiculita es una arcilla expandible poco estable que se hidrata y no es tan pegajosa, ni plástica como las montmorillonitas, por lo que presentan menores problemas de manejo que éstas. Las vermiculitas presentan una composición química muy variable, ya que parte del $\mathrm{Mg}^{2+}$ octaédrico puede ser sustituido por $\mathrm{Fe}^{3+}$ y $\mathrm{Al}^{3+}$. Este tipo de arcilla se identifica, una vez que se descarta la existencia de cloritas por tratamiento térmico a $500^{\circ} \mathrm{C}$, en aquellas muestras con reflejos basales de alrededor de 14-15 $\AA$; se puede determinar la presencia de vermiculitas al solvatar las muestras con etilenglicol y permanecer este reflejo basal invariable (Figura 5).

El mecanismo de formación más común de la vermiculita es la transformación de la mica negra o biotita por acidólisis parcial en ambientes particularmente húmedos (Besoain 1985, Wilson 


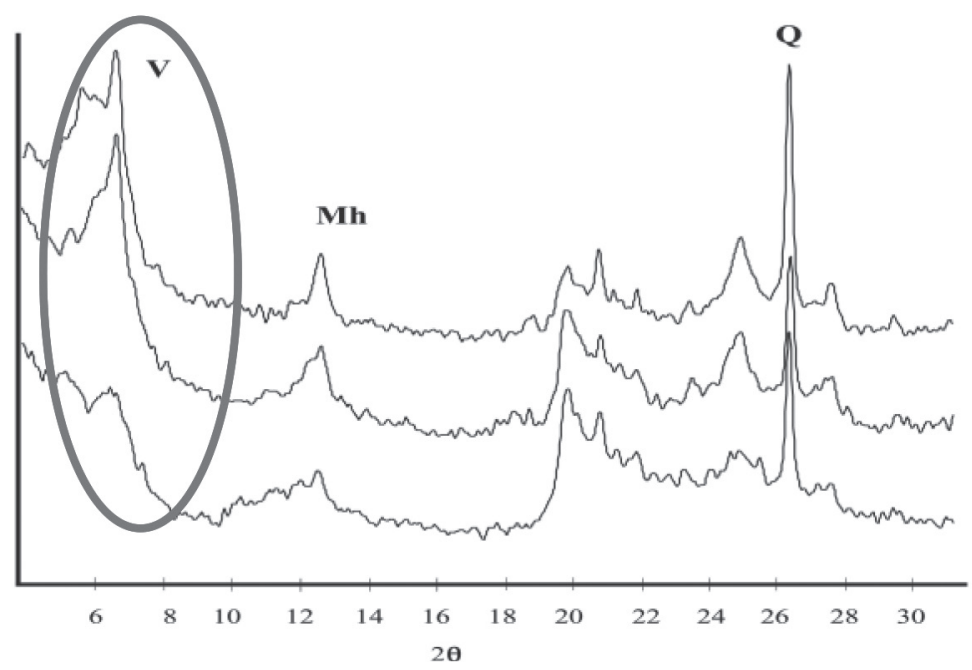

Fig. 5. Difractogramas de muestras glicoladas de 5 suelos en los que se identifican vermiculitas (V) con grados variables de cristalinidad, metahalloysita (Mh) y cuarzo (Q) (tomado de Arias et ál. 2010b).

1999). En climas templados y medios ligeramente ácidos, la biotita del suelo se transforma en vermiculita di-trioctaédrica por pérdida progresiva de $\mathrm{K}$ interlaminar y de $\mathrm{Mg}$ de la capa octaédrica, acompañada de oxidación del hierro ferroso, con destrucción de dicha capa y posterior reorganización. Su presencia podría explicarse además como producto de la transformación de esmectitas dioctaédricas de carga alta (Kautz y Ryan 2003).

En las llanuras del Caribe sureste la presencia de vermiculita asociada a la montmorillonita en proporciones casi similares ha sido documentada por varios autores (Stotzky y Martín 1963, Nieuwenhuyse 1996, Arias et ál. 2010b), que consideran su ocurrencia como producto de deposición fluviolacustre de vermiculita formada a partir de biotita en las rocas intrusivas (granodioritas, dioritas y monzonitas) en las partes altas de la cordillera de Talamanca (Mathers et ál. 1991). La vermiculita y vermiculitas interestratificadas también se han descrito en los suelos del Pacífico Central y Sur (Stotzky y Martín 1963, Ortiz y Collins 1992). Kautz y Ryan (2003) mencionan que la presencia de vermiculita es común (probablemente heredada de los materiales parentales) en los suelos lateríticos formados a partir de coladas de lava y depósitos aluviales de composición similar en las laderas y llanuras aluviales del Caribe de Costa Rica; la retención preferencial de $\mathrm{Mg}$ sobre $\mathrm{Na}$ y $\mathrm{Ca}$ en estos suelos se relaciona con la ocurrencia de vermiculita octaédrica y la posible sustitución de Fe en hidróxidos.

\section{Definición, características y procesos de formación de las cloritas}

Las cloritas son arcillas 2:1:1 interestratificadas compuestas por arcillas 2:1 a las que se une una capa de hidróxidos llamada brucita atraída por efecto electrostático, de manera que las arcillas 2:1 de carga neta negativa de la clorita originada por la sustitución de $\mathrm{Mg}$ por el $\mathrm{Al}$ se une a la lámina de brucita de carga positiva. Otra forma de unión que se puede dar en las cloritas es por medio de puentes de $\mathrm{H}^{+}$, pero en estos casos se da con menor estabilidad y es rápidamente destruida en los suelos. La CIC de estas arcillas es variable aunque generalmente baja, según su grado de meteorización, pero se puede tener una referencia de 10 a $40 \mathrm{cmol}(+) \cdot 1^{-1}$ de arcilla y una superficie específica efectiva entre 70 y 150 
$\mathrm{m}^{2} \cdot \mathrm{g}^{-1}$ (Porta et ál. 1994). Sánchez (1994) menciona la ocurrencia de montmorillonita asociada con clorita en la zona sur del país y Laguna (1985) las describe como clorita trioctaédrica producto de la acción hidrotermal y la meteorización de andesitas, latiandesitas y tufitas no diferenciadas en la cordillera de Tilarán y los Montes del Aguacate.

\section{Secuencias de formación de esmectitas}

Algunas secuencias y procesos de formación de esmectitas en Costa Rica ya han sido mencionadas anteriormente y se resumen en el Cuadro 2. En general, se puede concluir que las esmectitas descritas en el país se pueden formar a través de reacciones que ocurren en el suelo, es decir son de origen pedogenético (Winters 1997, Laguna 1985, Ortiz y Collins 1992, Fisher y Ryan 2006, Scheucher et ál. 2008, Arias et ál. 2010b) o geogenético (Bertolani y Loschi 1986, Berrangé et ál. 1990, Rochelle et ál. 1989, Mathers et ál. 1991, Sánchez 1994, Gaudín et ál. 2005, Hammarlund y Piñones 2009, Charpantier et ál. 2011).

En el caso de la formación pedogenética el proceso siempre ocurre en condiciones fluviolacustres a elevaciones inferiores a los $200 \mathrm{msnm}$, en regímenes de temperatura del suelo isohipertérmicos $\left(>24^{\circ} \mathrm{C}\right.$ durante todo el año) y preferiblemente en regímenes de humedad del suelo ústico (>90 días acumulativos secos durante el año); en estas condiciones y conforme al material parental, llegan a formarse montmorillonitas asociadas con vermiculitas interestratificadas y cloritas. Cuando el régimen de humedad del suelo es údico a ácuico el producto final dominante es la metahalloysita y la montmorillonita es más bien un mineral accesorio, excepto en la región sureste del Caribe, donde las montmorillonitas heredadas no llegan a formar Vertisoles pero si suelos con características vérticas. Cuando la formación de las esmectitas es geogenética, su saturación final depende de las condiciones lacustres (montmorillonita $\mathrm{Ca}$ ) ó marinas en que se formen (montmorillonita $\mathrm{Na}$ o montmorillonita $\mathrm{Fe}$ ).

En el caso de la formación geogenética, Laguna (1985) al estudiar la fracción arcilla de 59 muestras de rocas volcánicas del Terciario que afloran en la cordillera de Tilarán y los Montes del Aguacate, encontró que solamente 26 de ellas contenían hasta $5 \%$ de minerales arcillosos. La formación de los minerales secundarios ocurre por procesos de actividad hidrotermal (caolinita triclínica con poco desorden en la superposición de las capas estructurales), meteorización (caolinita muy desorganizada o "fire clay") o ambos (clorita trioctaédrica). El mineral de arcilla interestratificado illita/beidelita se forma por acción hidrotermal continuada sobre la ya formada beidelita (mineral dioctaédrico expandible rico en $\mathrm{Al}$ ) semejante a otros materiales conocidos como "intergrados cloríticos". Otros minerales como illita, pirofilita y metahalloysita se encuentran en muy poca proporción (Figura 6). Además Hammarlund y Piñones (2009) mencionan sobre exploraciones efectuadas a profundidades de hasta $4000 \mathrm{~m}$ de profundidad en el reservorio geotermal Miravalles que permitieron definir que superficialmente a $<165^{\circ} \mathrm{C}$ el producto de dicha acción tiende a formar esmectitas sobrepuestas a una capa intermedia de transición entre $140-220^{\circ} \mathrm{C}$ y que se encuentra sobre la zona de formación de illita a temperaturas inferiores a $\operatorname{los} 220^{\circ} \mathrm{C}$. 


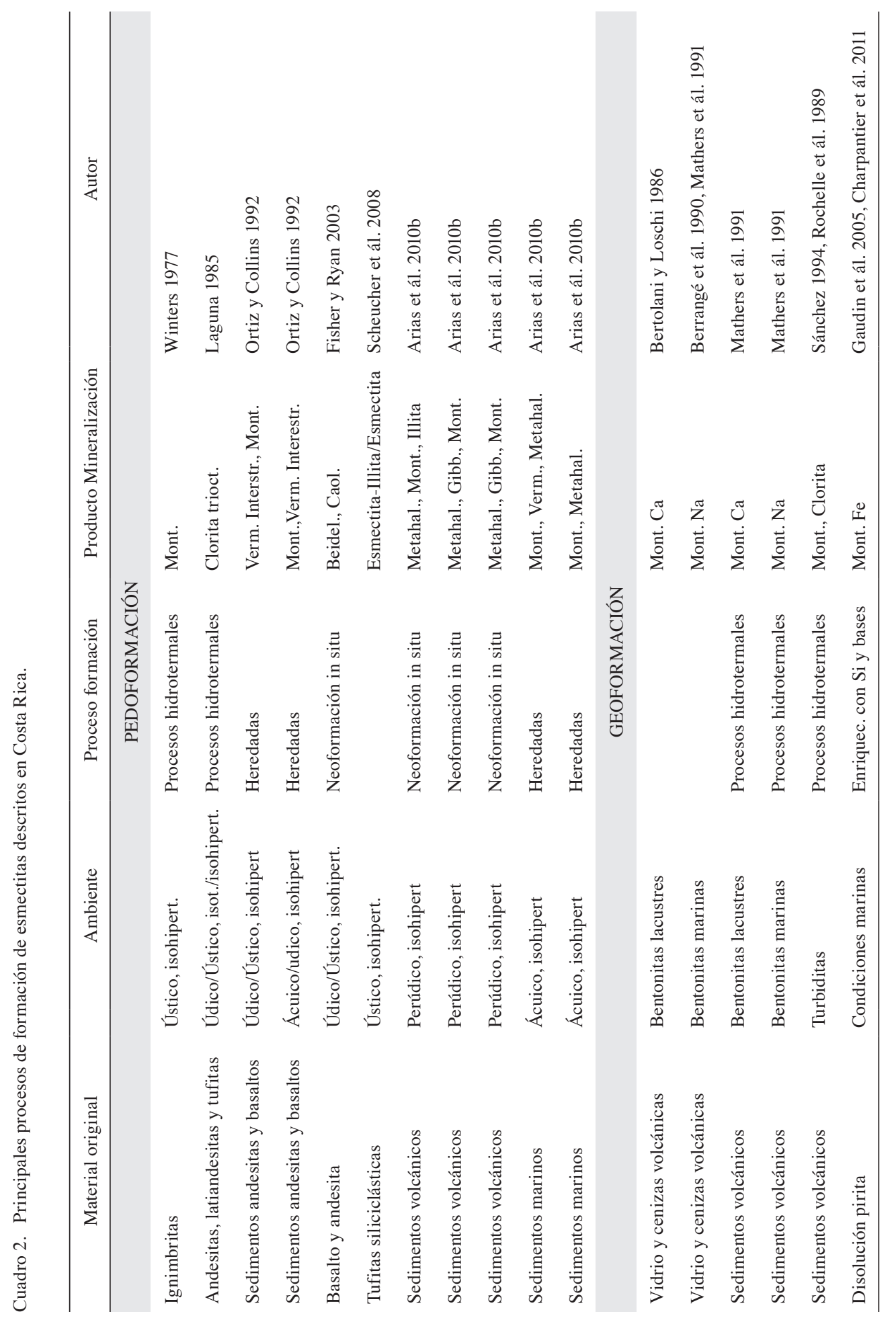




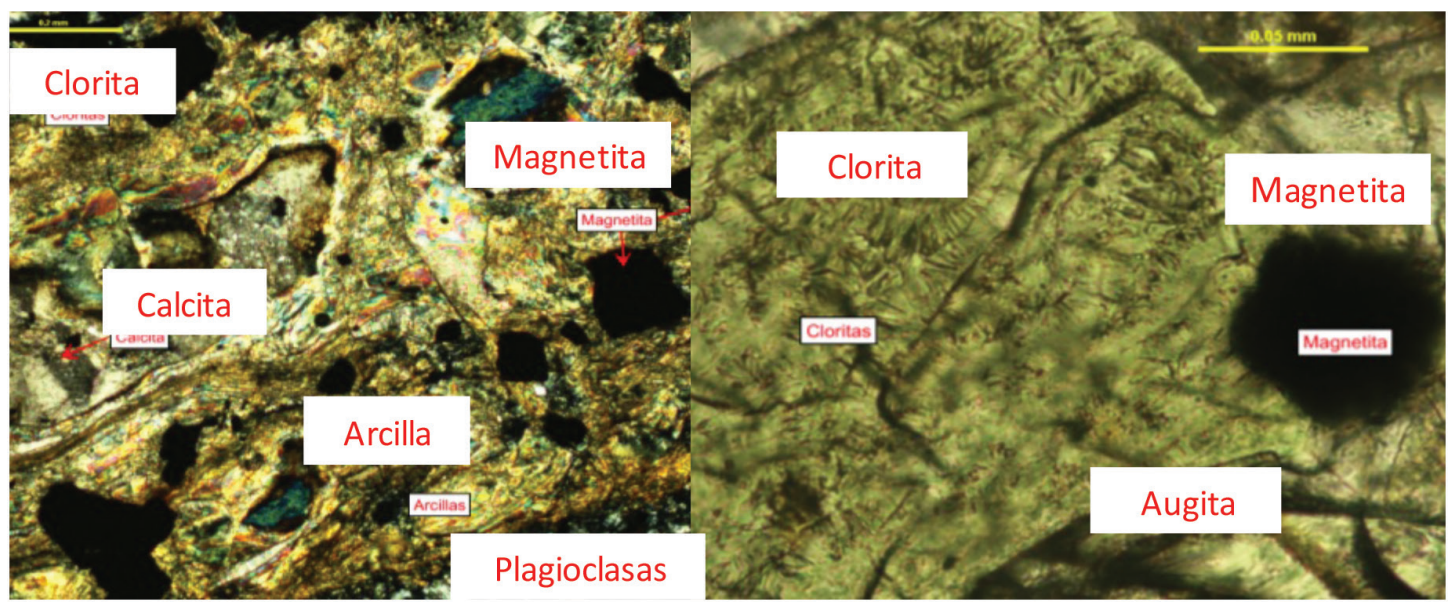

Fig. 6. Fotos al microscopio petrográfico de varios minerales primarios de la fracción arena muy fina.

\section{ALFISOLES, ULTISOLES Y OXISOLES (CAOLINITA-METAHALLOYSITA- HALLOYSITA-GIBBSITA-ÓXIDOS, HIDRÓXIDOS Y OXIHIDRÓXIDOS DE Fe Y Al)}

\section{Características delos sueloscaolinítico-oxídicos}

Los Alfisoles, Ultisoles y Oxisoles son los suelos más viejos y meteorizados del país, por lo que presentan pocos minerales primarios, formados sobre prácticamente casi cualquier tipo de material parental expuesto intermitentemente desde el Cretácico-Terciario hasta el presente y bajo el efecto prolongado de alta y relativamente constante temperatura y precipitación. Sin embargo las dataciones de diferentes horizontes de estos suelos permiten concluir que su formación se mantiene entre 9000 a 65000 años de acuerdo con la profundidad en que se determine la edad, es decir se ubican en el Pleistoceno-Holoceno (Kesel y Spicer 1985, Driese et ál. 2007, Pelt et ál. 2008).

El proceso de formación de los Alfisoles y Ultisoles normalmente se atribuye a un lavado intenso de solutos con translocación de arcilla desde el horizonte A hacia el horizonte B (Soil Survey Staff 2006) para formar pedones en su mayoría arcillosos pero que en su reología se comportan como si fueran arenosos (Schwartz
1998); lo anterior se atribuye a la formación de puentes de $\mathrm{H}^{+}$en las arcillas 1:1 que propicia que las partículas se agreguen entre sí dando estructuras recubiertas de óxidos de $\mathrm{Fe}$ y $\mathrm{Al}$ que permiten la formación de partículas de mayor tamaño conocidas como "pseudoarenas". Así, estos suelos también presentan bajos niveles de bases y $\mathrm{Si}$ y una acumulación de $\mathrm{Al}$ y $\mathrm{Fe}$; este último elemento, en su forma oxidada, es el que les confiere tonalidades pardo rojizas o rojizas. La pérdida de cationes en estos suelos ocurre por el fuerte lavado por la lluvia bajo varios tipos de vegetación (Krishnaswamy y Richter 2002, Boley et ál. 2009) en los abanicos aluviales y las terrazas del río General, excepto bajo cobertura de teca que tiende a acumular calcio, y la lixiviación de nitratos que se reduce significativamente cuando la mineralogía de arcilla es caolinítica en los horizontes superficiales pero cambia a gibbsítica con oxi-hidróxidos de $\mathrm{Fe}$ y $\mathrm{Al}$ en el subsuelo (Harmand et ál. 2010).

Por lo general estos suelos se encuentran en las partes medias y estables de las cuencas, en aquellas zonas que no han estado sujetas a proceso alguno de rejuvenecimiento y por el contrario han estado sometidas a constante lixiviación, así como en las laderas de las cordilleras donde además sufren de erosión de todo tipo. Mineralógicamente, presentan predominancia de arcillas 1:1 (principalmente caolinita) y óxidos de $\mathrm{Fe}$ y Al, 
con la gibbsita como miembro arcilloso producto final de la meteorización y en mayor cantidad en el subsuelo.

En el país, estos órdenes abarcan aproximadamente un $31 \%$ del área total (21\% Ultisoles, $10 \%$ Alfisoles); varios autores (Kesel y Spicer 1985, Nieuwenhuyse et ál. 2000, Kleber et ál. 2007, Wilcke et ál. 1999, 2000, USDA-SCS 2012) mencionan que algunos de los anteriormente llamados Ultisoles hoy en día clasifican como Oxisoles, aunque no mencionan su cobertura territorial. Las áreas principales de Alfisoles se ubican en la península de Nicoya donde se asocian con Vertisoles de la llanura de desborde del río Tempisque y en el Pacífico Central (Grecia, Atenas, Orotina y San Mateo) probablemente sobredimensionados en su área de cobertura.

Los Ultisoles se encuentran en la zona norte (Sarapiquí, San Carlos y Cutris), en el Pacífico sur (Pérez Zeledón y Buenos Aires y en las regiones fronterizas con Panamá). En las estribaciones de la cordillera de Talamanca hacia el Pacífico (cuenca del Térraba), Gómez y Chinchilla (2005) concluyen que el $70 \%$ de la superficie está conformada por Entisoles y Ultisoles y que la mineralogía de los pocos suelos estudiados por ellos muestra que los Ultisoles tienen caolinita como minerales secundarios dominante con cuarzo, gibbsita y hematita en menores cantidades. Holdridge et ál. (1971) en Volcán y Helechales mencionan la predominancia de gibbsita (50$70 \%$ ), caolinita $(30-50 \%)$ y trazas de vermiculita y alófana en los horizontes superiores y de halloysita (75\%), gibbsita (25\%) y trazas de montmorrillonita en los horizontes inferiores. Harmand et ál. (2010) además mencionan que en estos suelos la caolinita domina en la fracción arcilla de los horizontes superiores pero la gibbsita con oxihidróxidos de $\mathrm{Fe}$ y $\mathrm{Al}$ predominan en el subsuelo.

En la cordillera de Talamanca los Ultisoles también pueden encontrarse en las partes alta y media de las laderas empinadas y sobre terrazas antiguas de los ríos que la drenan (Macías 1969, Araya 1979, Kesel y Spicer 1985, Mata y Ramírez 1999, Cubero 2002, Gómez y Chinchilla 2005, Driese et ál. 2007, Pelt et ál. 2008, Harmand et ál. 2010), en las cuales según Salazar (2012) dominan las mineralogías oxídico-caoliníticas, al menos en los 22 perfiles descritos por el autor en la cuenca del río Savegre. La mineralogía de arcillas de los horizontes A de 22 perfiles de la cuenca del río Savegre fue estudiada por Salazar (2012) en suelos que según Cubero (2002) corresponden a Typic Haplohumults y Palehumults (55,4\%), Fluventic Eutrudepts (3,5\%), Typic Udifluvents, Typic y Lithic Udorthents $(36,9 \%)$ y Lithic Haplohemists (4,0\%). Salazar (2012), analizó siete suelos de las secciones alta y media de la cuenca y 8 de la parte baja de la misma, donde se encontró que: (1) en los horizontes A los suelos menos evolucionados de la parte alta de la cuenca, la mineralogía de arcillas tiende a estar dominada por caolinita asociada con halloysita, vermiculita y esmectita siempre en presencia de cantidades importantes de cuarzo y en algunas ocasiones de material calcáreo (dolomita o calcita); (2) en los suelos más meteorizados de la cuenca alta, la mineralogía tiende a estar dominada por caolinita con gibbsita y cuarzo y en la misma parte de la cuenca, (3) en los horizontes B la fracción arcillosa consiste de caolinita asociada con clorita, vermiculita, esmectita y halloysita y en menor cantidad gibbsita, goethita y feldespatos potásicos; (4) los minerales arcillosos dominantes en los horizontes A de los suelos más desarrollados de la cuenca media del río Savegre contienen como arcilla dominante caolinita asociada con cuarzo caolinita, halloysita y cuarzo; (5) en los suelos de desarrollo medio a moderado y en los menos desarrollados caolinita, cuarzo, halloysita asociadas con clorita, vermiculita y esmectita; (6) en todos los casos suele encontrarse pequeñas cantidades de gibbsita, goethita y plagioclasa, sobre todo en los horizontes B; (7) en la parte baja de la cuenca la mineralogía de la fracción arcillosa de los horizontes A tiende a ser dominada por caolinita asociada con halloysita, clorita, vermiculita y esmectita y en menor escala plagioclasas y goethita; (8) en algunas ocasiones en el horizonte $\mathrm{B}$ de estos suelos también pueden encontrarse pequeñas cantidades de gibbsita. 
En la vertiente Caribe de la cordillera de Talamanca se describen como dominantes los Ultisoles asociados con Inceptisoles y Entisoles (Núñez 1986, Hyman 1997, Winowiecki 2008). Solamente Winowiecki (2008) menciona que la caolinita se encuentra en todos los suelos estudiados, arcilla que puede ser heredada de los materiales parentales de la zona o formada por meteorización de algunos de sus minerales (p.e. feldespatos), la gibbsita se encuentra en los horizontes inferiores de 2 perfiles de las cimas, asociada con los valores más altos de saturación de $\mathrm{Al}$, que indican el alto grado de meteorización de estos suelos; bajo estas condiciones, además suelen presentarse arcillas 2:1:1 (intercaladas con hidróxidos de $\mathrm{Al}$ ). En los suelos de las pendientes medias, domina la caolinita como único mineral arcilloso presente, resultado de la meteorización de los filosilicatos 2:1 presentes en el material parental. En los suelos del piedemonte y la llanura de inundación domina la esmectita asociada a mica y caolinita, que denotan la acumulación de Si proveniente del lavado que ocurre en los suelos de las partes más altas del relieve. Cuatro pedones en diferentes posiciones topográficas, presentan picos anchos a los rayos $\mathrm{X}(7,3-8,8 \mathrm{~nm})$ lo que sugiere la presencia de minerales intergradados caolín-mica y que a su vez indica que la mica actúa como fuente/sitio de la cual se forma la caolinita.

\section{PRINCIPALES TIPOS DE ARCILLA EN ALFISOLES, ULTISOLES Y OXISOLES}

En la Figura 7 se presenta la distribución espacial de suelos con mineralogía dominante oxídico caolinítica, donde sobresalen los Ultisoles y los Alfisoles con presencia en algunos sitios de Oxisoles.

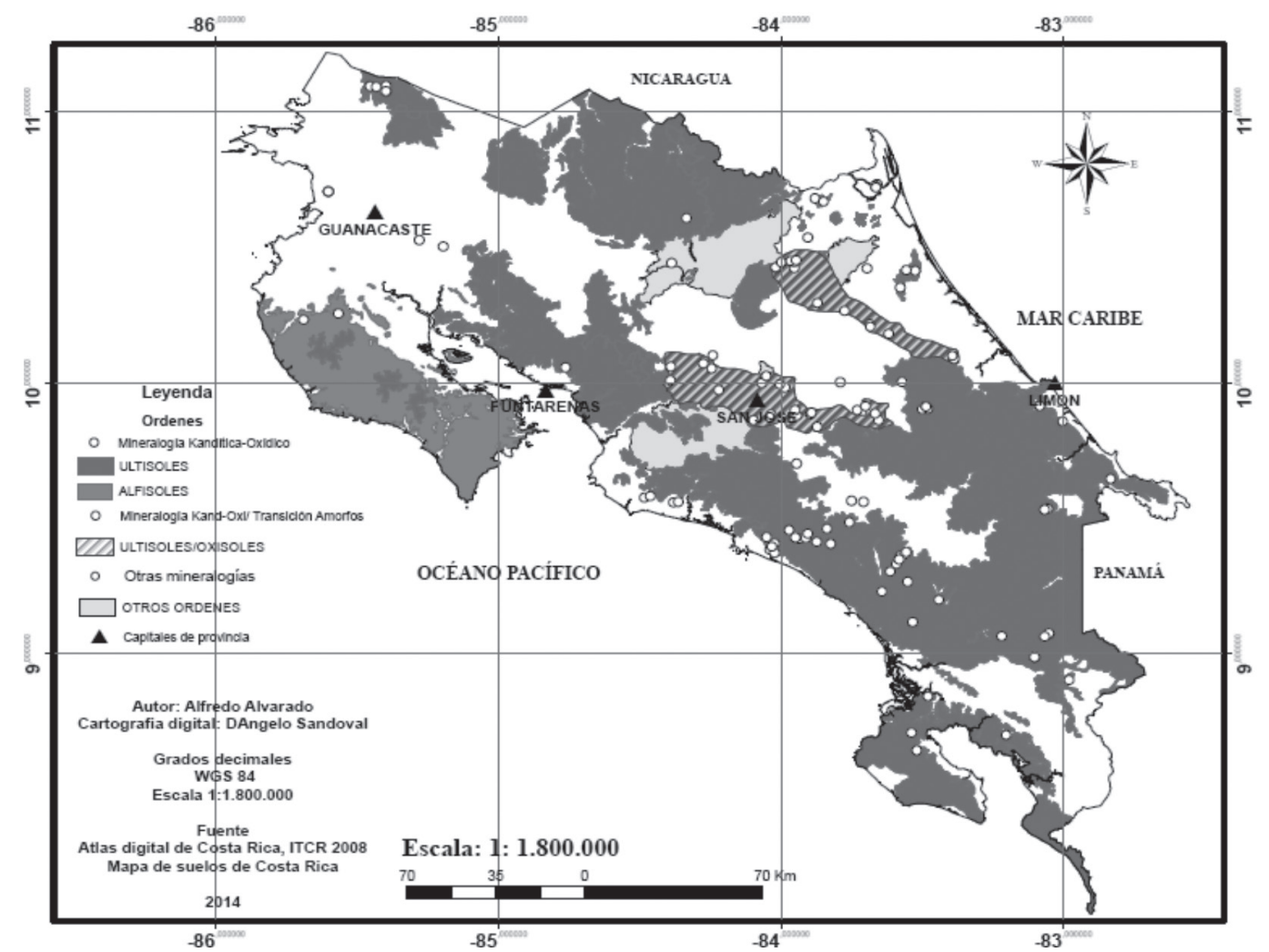

Fig. 7. Distribución espacial de suelos en Costa Rica con mineralogía dominante oxídico caolinítica, donde sobresalen los Ultisoles y los Alfisoles con presencia en algunos sitios de Oxisoles. 


\section{Definición, características y procesos de formación de las caolinitas}

Los minerales de este grupo son aluminosilicatos pobres en sílice (Porta et ál. 1994) caracterizados por láminas alternas de tetraedros de Si y octaedros de Al, unidas entre sí por puentes de $\mathrm{H}^{+}$, lo que hace que su red sea rígida y no se dilaten (Figura 8); a su vez las 2 láminas de cada unidad están unidas por átomos de oxígeno libres de cada octaedro (Besoain 1985).

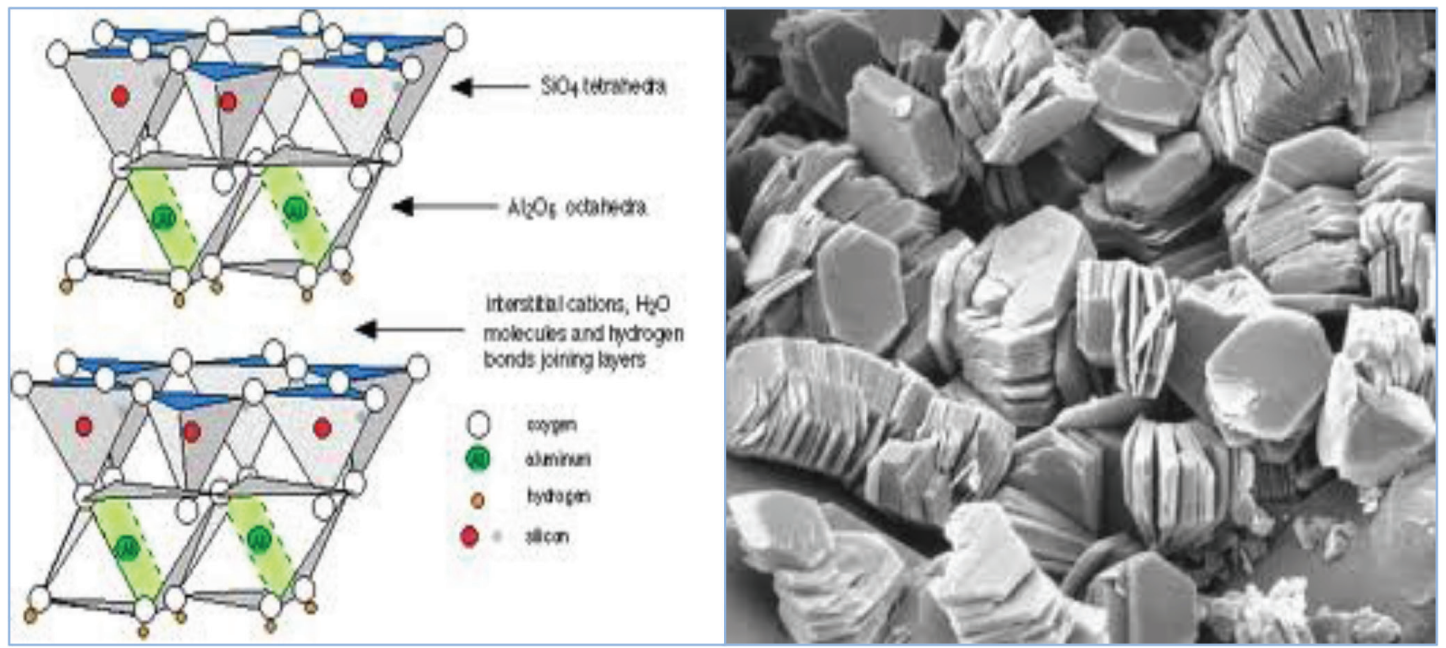

Fig. 8. Diagrama esquemático y de foto microscopía electrónica de la caolinita.

La caolinita no presenta sustituciones isomórficas significativas, por lo que la estructura es eléctricamente neutra y presenta baja actividad física. Este tipo de arcilla presenta una baja CIC (3 y $15 \mathrm{cmol}(+) \cdot \mathrm{l}^{-1}$ arcilla), superficie específica (7 a $30 \mathrm{~m}^{2} \cdot \mathrm{g}^{-1}$ ), baja plasticidad y cohesión, lo que permite el lavado fácil de cationes en los ecosistemas húmedos y calientes donde predominan.

En Costa Rica la caolinita tiende a dominar en las cimas y laderas de montaña de casi todo el país, donde se presentan materiales geológicos del Terciario y condiciones lluviosas que producen un fuerte lavado de cationes (Schwartz 1998); bajo estas condiciones se asocian con gibbsita y en algún momento histórico se pensó en su explotación para fines de extracción de aluminio (Castillo 1997). Winters (1997) considera que los altos contenidos de $\mathrm{Si}$ en el vidrio de la ignimbrita, bajo las condiciones ústicas de Guanacaste, favorecen la formación de arcillas tipo 1:1 como la halloysita y la caolinita y probablemente de algunos minerales no cristalinos que bajo las condiciones climáticas imperantes en la zona tienden a formar arcilla 2:1 en posiciones depresionales en suelos grisáceos.

Datos del Departamento de Agricultura de los Estados Unidos (USDA-SCS 2012) obtenidos en muestras de 4 Ultisoles del valle del río General indican que en 3 de las muestras dominaba la caolinita con pequeñas cantidades de gibbsita y goethita, mientras que en la cuarta muestra dominaban halloysita y gibbsita. En la misma región, Kesel y Spicer (1985) encontraron que en los Oxisoles formados sobre los depósitos más antiguos dominaba la gibbsita en presencia de caolinita. Un poco más al sur, Pacheco (1990) indica que las arcillas principales son caolinita y metahalloysita (30-50\%), con un $10-30 \%$ de gibbsita y $1-10 \%$ de hematita y goethita. En la misma región, Schwartz (1998) describe 2 suelos 
considerados como Ultisoles de textura fina en los cuales la fracción de arcilla gruesa consiste principalmente de caolinita y cuarzo y pequeñas cantidades de goethita, mientras que la fracción de arcilla fina está dominada por caolinita con cantidades muy pequeñas de esmectita y goethita.

Scheucher et ál. (2008) menciona que en la región sureste de la finca La Gamba se forman

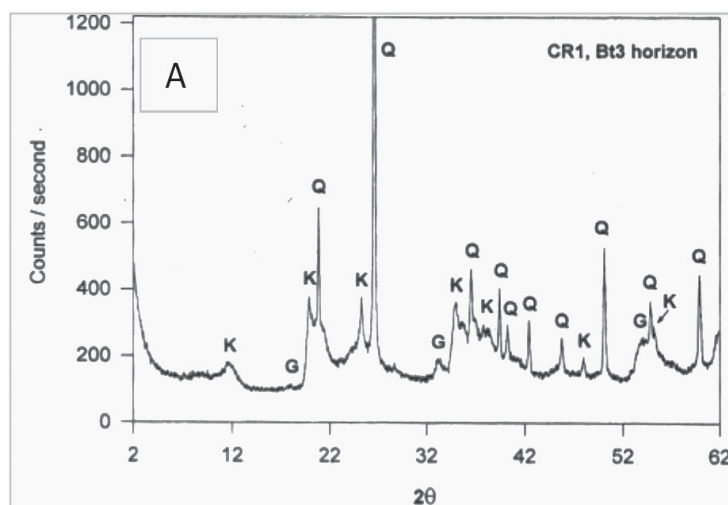

Oxyaquic Eutrudepts bajo una meteorización incipiente que permite la formación de caolinita-esmectita-feldespato sin trazas de cuarzo en los valles intermontanos y Ultisoles en las laderas de la finca donde la caolinita, acompañada de pequeñas cantidades de gibbsita, domina la secuencia caolinita-esmectita anteriormente descrita (Figura 9).

Fig. 9. Patrón de difracción de rayos X de la fracción arcilla de un Oxyaquic Hapludults en Guadalupe de Pérez Zeledón dominado por: A) caolinita $(\mathrm{K})$, cuarzo $(\mathrm{Q})$ y goethita $(\mathrm{G})$ y B) maghemita o magnetita $(\mathrm{M})$. (tomado de Schwartz 1998).

\section{Definición, características y procesos de formación de la gibbsita y otros óxidos e hidróxidos de hierro y aluminio}

Gibbsita: La gibbsita (hidróxido de aluminio), se considera como el producto final y consecuencia de la desbasificación y desilicación por meteorización de aluminosilicatos como plagioclasas y piroxenos y la acumulación de hidróxidos de aluminio en suelos con $<0,5 \mathrm{mg} .1^{-}$ ${ }^{1} \mathrm{Si}$ en solución (Nakamura y Sherman 1965, Besoain 1985, Nieuwenhuyse et ál. 1994, Kautz y Ryan 2003, Kleber et ál. 2007, Arias et ál. 2010a). Scheucher et ál. (2008) encontraron que en la región noroeste y en las cimas de la Fila Gamba (Typic Hapludults) domina la gibbsita y en otras posiciones de la pendiente de la fila una secuencia esmectita, illita-esmectita (interestratificada) y en menor proporción zeolita transformada diagenéticamente.
Kleber et ál. (2007) mencionan que, desde el punto de vista pedogenético, la gibbsita es un mineral termodinámicamente más estable que la halloysita en el trópico húmedo y caliente y que su formación y acúmulo en el subsuelo se deben a la pérdida de $\mathrm{Si}$ y acumulación de Fe y Al (gibbsita). El aumento de los contenidos de gibbsita con la profundidad del suelo ocurre en Ultisoles en ambiente ústico (Schwartz 1998) y Oxisoles en ambiente perúdico de Costa Rica (Kleber et ál. 2007). La presencia de gibbsita en el horizonte B puede identificarse por su reacción con el fluoruro de sodio, lo que permite separar los Ultisoles de los Oxisoles de Brasil (Alves y Lavorenti 2004).

En la cuenca del río General, varios autores han descrito la existencia de gibbsita en cantidades apreciables. USDA-SCS (2012) mencionan que en 3 Ultisoles del Valle del General 
encontraron caolinita, gibbsita y goethita, los últimos 2 en pequeñas cantidades y en una cuarta muestra halloysita y gibbsita. En el mismo valle Kesel y Spicer (1985) encontraron que en los Oxisoles formados sobre los depósitos más antiguos, la mineralogía prevalente consiste en una dominancia de gibbsita en presencia de caolinita y en los Ultisoles de Buenos Aires de Puntarenas, Pacheco (1990) indica la presencia de un 10 a $30 \%$ de gibbsita.

En suelos de las cuencas de los ríos Tortuguero y Reventazón, la abundancia de la gibbsita es relativamente alta y está asociada con alófana en 2 horizontes superficiales de los suelos donde se asocia a cantidades bajas de alófana, formándose por debasificación y desilicación de arenas andesíticas del Cuaternario con contenidos altos de plagioclasas y piroxenos (Nieuwenhuyse et ál. 1994, Arias et ál. 2010a). En esta región Arias et ál. (2010a) encontraron gibbsita y trazas de hematita maghemita, magnetita y ferrihidrita; la ferrihidrita se encontró solamente en un perfil, mientras que la maghemita y la magnetita se identificaron asociadas entre sí, o bien mezcladas con hematita. Sobre formaciones geológicas del Terciario en la misma región, varios autores (Holdridge et ál. 1971, Nieuwenhuyse 1996, Nieuwenhuyse et ál. 1994) reportan la presencia de gibbsita en algunos sectores de Barra de Colorado, donde Anderson y Byers (1931) mencionaran que la fracción arcilla de la serie de suelos Colombiana es alta en contenido de óxidos de $\mathrm{Fe}$ y Al. Van Dooremolen et ál. (1990) y Nieuwenhuyse y van Bremen (1997) mencionan que en los suelos desarrollados sobre lahares en las llanuras del Caribe, de más de 2000 años se incrementa el contenido de complejos organominerales en el horizonte A y la formación de halloysita y gibbsita y óxidos e hidróxidos de $\mathrm{Fe}$ y $\mathrm{Al}$ a expensas de la alófana en el horizonte B (Figura 10). La presencia de depósitos relacionados con cenizas volcánicas en el Caribe noroeste se asocia a la actividad del complejo o gran campo volcánico del Irazú-Turrialba y al vulcanismo de volcanes de actividad tardía en la cordillera de Talamanca del Plio-Pliestoceno.

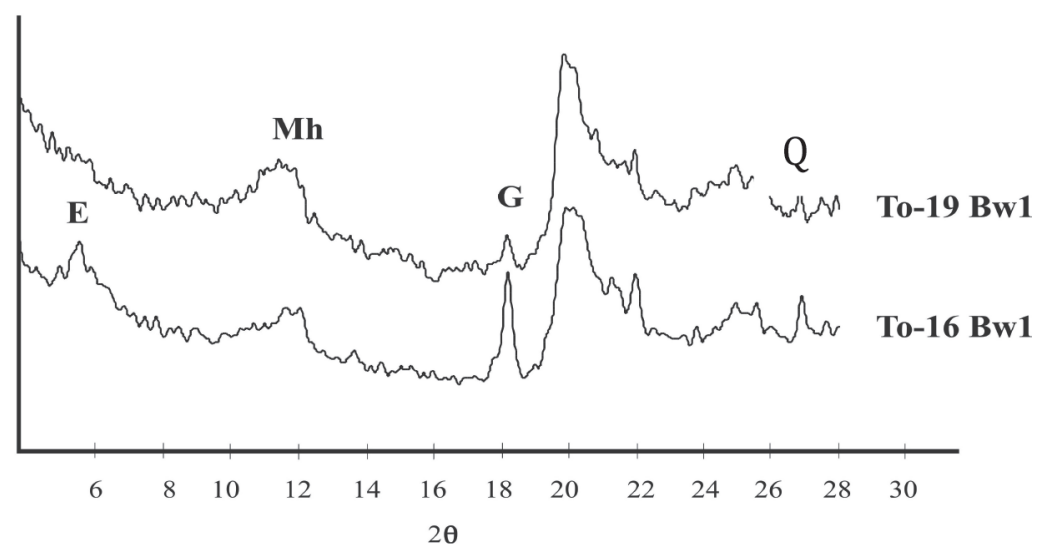

Fig. 10. Difractograma de 2 suelos en los que se identifican gibbsita (G),metahalloysita (Mh), esmectita (E) y cuarzo (Q) en las llanuras del Caribe, Costa Rica (tomado de Arias et ál. 2010b).

Otros óxidos e hidróxidos: En este conjunto de minerales secundarios se agrupan los óxidos e hidróxidos de $\mathrm{Fe}$ y $\mathrm{Al}$ del tamaño de las arcillas. La gibbsita sería un ejemplo de hidróxido de $\mathrm{Al}$, mientras que ejemplos de óxidos, oxihidróxidos e hidróxidos de Fe son la goethita, hematita, ferrihidrita, lepidocrocita y maghemita. Los óxidos de Fe (término en el que se incluyen 
normalmente óxidos, oxihidróxidos e hidróxidos) son primero poco cristalinos e hidratados y luego cristalizan de acuerdo con la temperatura o a las condiciones redox para formar minerales como la goethita o hematita. Los suelos dominados por este tipo de materiales presentan baja plasticidad, fácil laboreo y bajo potencial nutricional. La carga eléctrica de los óxidos de Fe y Al se genera por desprotonación de los grupos $\mathrm{OH}^{-}$superficiales, ya sea en un medio ácido ( $\mathrm{pH}$ menor al punto isoeléctrico) donde presentan carga positiva (alta CIA) y pueden fijar por ejemplo fosfato o sulfatos, o en un medio ligeramente más básico ( $\mathrm{pH}$ mayor al punto isoeléctrico) donde presentan carga negativa y aumentan la CIC, aunque de forma escasa.

Los trabajos de Wilcke et ál. (1999, 2000) tratan de las propiedades y formas de acumulación de óxidos de hierro y aluminio, así como la distribución de los metales $\mathrm{Al}, \mathrm{Cd}, \mathrm{Cu}, \mathrm{Fe}, \mathrm{Mn}$, $\mathrm{Pb}$ y $\mathrm{Zn}$ en 8 Oxisoles, 5 Andisoles, 2 Mollisoles y 2 Alfisoles dedicados al cultivo del café en varias partes del país, factores considerados como un indicador de su meteorización y génesis, amén de su contaminación antropogénica. Los autores encontraron que las concentraciones totales de $\mathrm{Al}$ principalmente de origen geo-pedogenético (promedios de 76 g. $\mathrm{kg}^{-1}$ en el horizonte A y de 106 g. $\mathrm{kg}^{-1}$ en el horizonte muestreado más profundo) y de Fe (A: 56 g. $\mathrm{kg}^{-1}$, B: 66 g. $\mathrm{kg}^{-1}$ ) generalmente aumentaron con la profundidad de los suelos. Las concentraciones totales de Cd (A: 0,14 g. $\mathrm{kg}^{-1}$, B: 0,09 g. $\mathrm{kg}^{-1}$ ) y de $\mathrm{Pb}(\mathrm{A}:$ 7,3 g.kg-1 , B: 5,5 g.kg-1) son mayores en los horizontes superiores de la mayoría de los perfiles, que muestran probablemente, las adiciones antropogénicas. Las concentraciones promedio de los elementos $\mathrm{Mn}$ (A: 1190 g.kg-1 ${ }^{-1}$ B: 1150 g.kg-1 $)$ y Zn (A: 59 g. $\mathrm{kg}^{-1}$, B: 66 g. $\mathrm{kg}^{-1}$ ) variaron muy poco con la profundidad de los suelos comparados. Sin importar que el $\mathrm{Cu}$ se aplica como fungicida regularmente en las plantaciones de café, la concentración total de este elemento (A: 135 g.kg-1 ${ }^{-1}$ B: 158 g. $\mathrm{kg}^{-1}$ ) mostró una acumulación solo en el horizonte $\mathrm{A}$ en 3 de los perfiles estudiados, probablemente Mollisoles. Mata y Ramírez (1999), encontraron que en los horizontes B de plantaciones de café sobre Andisoles del Valle Central la concentración de $\mathrm{Cu}$ extraído con el método de Olsen modificado aumenta de 20 a 55 mg. ${ }^{-1}$. Wilcke et ál. (1999) estudiaron la concentración de los mismos metales en los agregados de los horizontes A como un todo, en su interior y en su exterior, donde encontraron que la concentración total de $\mathrm{Al}, \mathrm{Cd}, \mathrm{Cu}$, $\mathrm{Fe}, \mathrm{Mn}, \mathrm{Pb}$ y $\mathrm{Zn}$ es mayor en la superficie exterior de los agregados, excepto por el $\mathrm{Zn}$ debido a la desilicación preferencial del exterior de los agregados y a la sorción principalmente de formas fácilmente extraíbles de los metales pesados en estas superficies.

\section{Secuencias de meteorización en Ultisoles, Alfisoles y Oxisoles}

Sak et ál. (2004b), al estudiar la meteorización de basaltos extraídos del subsuelo de las terrazas de la región Esterillos-Parrita encontraron que la conversión de minerales de basaltos no alterados (plagioclasas y augita) a minerales autigénicos en los anillos porosos de la roca (caolinita, alofana, gibbsita y oxi-hidróxidos de $\mathrm{Fe}$ ) es iso-volumétrica, con los elementos $\mathrm{Ti}$ y $\mathrm{Zr}$ inmóviles. La pérdida de elementos por lavado sigue el orden $\mathrm{Ca} \approx \mathrm{Na}>\mathrm{K} \approx \mathrm{Mg}>\mathrm{Si}>\mathrm{Al}>$ $\mathrm{Fe} \approx \mathrm{P}$. El perfil de alteración estudiado en los anillos de meteorización de la roca, sugiere la disolución de plagioclasas y augita para formar caolinita, la cual se disuelve para formar un precipitado de gibbsita con el envejecimiento de los anillos de borde de la roca; sin embargo esta explicación es incongruente con los criterios expresados por Sposito (1989). Como resultado de la intensa meteorización de esta región Fisher y Ryan (2006) mencionan que los cationes se lixivian en el orden $\mathrm{Ca}>\mathrm{Na}>\mathrm{Mg}>\mathrm{K}>\mathrm{Si}>\mathrm{Al}$ $>\mathrm{Fe}>\mathrm{Ti}>\mathrm{Zr}$, con una acumulación residual de $\mathrm{Fe}, \mathrm{Al}, \mathrm{Zr}$ y Ti; las pérdidas de cationes y $\mathrm{Zr}$ tienden a estabilizarse a los $37 \mathrm{ka}$ que indican una pérdida de masa por denudación química de $\approx 50 \%$ en $125 \mathrm{ka}$.

Scheucher et ál. (2008) al estudiar la mineralogía y el producto final de la meteorización de rocas y suelos en la Finca Experimental La 
Gamba, Golfo Dulce, encontraron 5 litologías sedimentarias: 1) tufitas siliciclásticas verdosas de grano fino (dominantes en términos de superficie cubierta); 2) arenas semiconsolidadas; 3) caliza micrítica gris azulada; 4) lodolitas rojas y 5) arcillas grisáceas. Los autores consideran que la presencia de esmectita en todos los sedimentos siliciclásticos indica la existencia de una importante pero variable cantidad de material volcanoclástico, intuida por la presencia de anfíboles, plagioclasas, piroxenos y olivino en los horizontes superficiales de varios suelos. El área estudiada está dividida de noreste a suroeste por una quebrada que sigue el fallamiento principal de la región, de manera que los materiales de la formación de tufitas siliciclásticas se encuentran en la parte noroeste de la falla y los demás materiales en la zona ocurren principalmente al sureste de la misma. Los suelos que dominan en la región noroeste son Ultisoles (Typic Hapludults) arcillosos con alto contenido de cuarzo, dominados por gibbsita cuando ocurren en las cimas del "Miembro Fila Gamba", sección superior de la formación geológica Quebrada Achiote, y por una secuencia esmectita, illita-esmectita (interestratificada) y en menor proporción zeolita transformada diagenéticamente. Principalmente en la región sureste, formada a partir de materiales de las formaciones geológicas Quebrada Achiote y Golfito, la fracción arcilla de los suelos no contiene cuarzo con una meteorización incipiente que está representada por la presencia de caolinitaesmectita-feldespato en los Inceptisoles (Oxyaquic Eutrudepts) de los valles intermontanos; en los Ultisoles de las laderas, la secuencia caolinitaesmectita está dominada por capas de caolinita y cuando ocurre una meteorización intensa se presentan pequeñas cantidades de gibbsita. Aunque la ausencia de halloysita en todos los suelos estudiados, se considera causada por la presencia en la zona de un período seco de 1 a 2 meses que inhibe su formación, el concepto no es válido ya que Weissenhofer y Huber (2008) consideran que en la región no se presentan períodos con déficit de humedad y otros autores si han encontrado halloysita en suelos similares de la zona (Stotzky y Martín 1963, Holdridge et ál. 1971).

Fiskell e Iley (1961) encontraron en una muestra tomada de un probable Ultisol de ladera en New Castle, Limón, una mineralogía caolinítica y bastante material amorfo, posiblemente sesquióxidos provenientes de cenizas recientemente depositadas sobre el mismo. En el estudio de Krezdorn et ál. (1967) algunos Ultisoles de la región de Limón, tenían una mineralogía consistente en caolinita, halloysita y cuarzo. En otro estudio USDA-SCS (2012) se reconocen 3 Ultisoles en Tuis de Turrialba, Paraíso y Río Frío en los que el mineral arcilloso dominante se identificó como caolinita con cantidades menores de gibbsita y goethita.

Los trabajos sobre mineralogía de arcillas realizados en la Zona Sur del país mencionan la presencia de caolinita, gibbsita y goethita, con pequeñas cantidades de halloysita y gibbsita (USDA-SCS 2012). Al estudiar depósitos aluviales en el valle del río General, Kesel y Spicer (1985) encontraron que los depósitos más antiguos, clasificados como Oxisoles, tenían una mineralogía con dominancia de gibbsita en presencia de caolinita. En los Ultisoles de Buenos Aires de Puntarenas, Pacheco (1990) indica que las arcillas principales son caolinita, gibbsita y hematita y goethita.

\section{CONCLUSIONES GENERALES}

La génesis de los suelos de Costa Rica se ve afectada por varios procesos, según la elevación a la que se estén formando. En las partes altas de las cordilleras dominan la andosolización y la podsolización, mientras que en las laderas intermedias a bajas tienden a dominar los procesos de laterización y en las partes bajas, la acumulación de materiales erosionados de las laderas. Como resultado final de los procesos de formación de suelo, en el Cuadro 3 se presenta el análisis químico total de 10 horizontes superficiales de cada uno de los siguientes órdenes de suelos de Costa Rica: Andisoles, Inceptisoles, Vertisoles y Ultisoles (Alvarado y Mata 1993). Si 
Cuadro 3. Contenidos elementales totales del horizonte superficial de los principales órdenes de suelos de Costa Rica, promedio de 10 muestras para cada orden (Alvarado y Mata 1993).

\begin{tabular}{|c|c|c|c|c|}
\hline \multirow{2}{*}{ Elemento } & Andisol & Inceptisol & Vertisol & Ultisol \\
\hline & \multicolumn{4}{|c|}{ Concentración total (\%) } \\
\hline $\mathrm{Si}$ & 23,47 & 23,37 & 23,11 & 19,92 \\
\hline $\mathrm{Al}$ & 12,1 & 11,85 & 9,36 & 14,52 \\
\hline $\mathrm{Fe}$ & 6,97 & 9,73 & 10,21 & 10,85 \\
\hline $\mathrm{Ca}$ & 1,95 & 1,22 & 1,54 & 0,06 \\
\hline $\mathrm{Mg}$ & 1,01 & 1,14 & 1,44 & 0,6 \\
\hline $\mathrm{Ti}$ & 0,71 & 0,84 & 0,85 & 0,89 \\
\hline K & 0,8 & 0,5 & 0,15 & 0,25 \\
\hline $\mathrm{Na}$ & 1,06 & 0,34 & 0,19 & 0,04 \\
\hline Mn & 0,12 & 0,21 & 0,18 & 0,43 \\
\hline $\mathrm{P}$ & 0,21 & 0,09 & 0,05 & 0,08 \\
\hline
\end{tabular}

se acepta la hipótesis de que los Andisoles son de origen reciente y por ende menos meteorizados que los Inceptisoles y que como miembros terminales de la meteorización en climas tropicales estacionalmente secos se forman los Vertisoles y en los de clima tropical lluvioso los Alfisoles, Ultisoles y Oxisoles pueden entonces estudiarse los cambios ocurridos por meteorización con los siguientes resultados:

En los Ultisoles los contenidos de $\mathrm{Fe}$, Mn y Ti son relativamente mayores a los encontrados en los otros órdenes de suelos, elementos que tienden a acumularse con el tiempo de meteorización (Wilcke et ál. 1999, 2000).

- $\quad$ La relación $\mathrm{Si} / \mathrm{Al}$ más alta $(2,45)$ de los Vertisoles refleja la composición de la fracción arcilla esmectítica. En este orden también se nota una alta acumulación de $\mathrm{Ca}, \mathrm{Mg}$ y $\mathrm{Fe}$.

- En las llanuras aluviales de Caribe noroeste las arcillas más abundantes son halloysita y metahalloysita con trazas de materiales de corto rango de cristalización (amorfos), gibbsita y montmorillonita; en los suelos rojos más evolucionados cerca de Colorado y en suelos meteorizados, se encuentran halloysita, gibbsita y trazas de caolinita. Las arcillas más representativas de las llanuras del Caribe sureste son las montmorillonitas, con menor ocurrencia de halloysitas, metahalloysitas y caolinitas. En los suelos derivados de las ignimbritas con influencia de cenizas volcánicas depositadas recientemente se enmarcan mayoritariamente dentro de los órdenes Entisoles que ocupan los relieves más escarpados y erosionados y que clasifican como Typic y Lithic Ustorthents El segundo orden por área cubierta son los Inceptisoles en secciones medias y bajas de los terrenos ligeramente ondulados a ondulados y que incluyen los Typic, Vertic, Fluventic y Andic Haplustepts, Typìc y Fluventic Dystrustepts, Andic Humustepts y Aeric Endoaquepts. En las regiones plano cóncavas del relieve, tienden a dominar los Vertisoles, entre ellos los Typic y Chromic Haplusterts y Ustic Epiaquerts en menor escala asociados con Dystric Hapludands. Con poca frecuencia, sobre este tipo de material parental pueden encontrarse Mollisoles, Alfisoles y Ultisoles en ciertos 
lugares específicos. La génesis indica una meteorización de las tobas para formar un epipedón ócrico que puede evolucionar a móllico con el tiempo y endopedones cámbicos que pueden evolucionar a argílicos siempre y cuando no se acumule arcillas de tipo 2:1, en cuyo caso tienden a formarse los Vertisoles o subgrupos vérticos de otros órdenes.

\section{AGRADECIMIENTOS}

A los Drs. Raúl Zapata, Juan Carlos Loaiza, José Torrent y Lolita Campos por la revisión y recomendaciones hechas al presente trabajo. De la misma manera se extiende el agradecimiento a los Ings. Jesús Fernández, Wellins Durango y Oldemar Vargas por su ayuda en la revisión de los borradores del documento y a la Asociación Costarricense de la Ciencia del Suelo por el financiamiento parcial que permitió la contratación de D’Angelo Sandoval Chacón, a quien se agradece la colaboración en el manejo de la base de datos y la confección de los mapas.

\section{LITERATURA CITADA}

AHN P.M., ELLIOT C.R (eds.). 1989. Vertisols management in Africa. International Board for Soil Research and Management. IBSRAM Proceedings No. 9. Tahiland. $421 \mathrm{p}$.

ALVARADO A., MATA R. 1993. Análisis químico total de suelos por espectrometría de fluorescencia de rayos X. In. IX Congreso Nacional Agronómico y de Recursos Naturales. San José, Costa Rica. Vol. II-(2):230.

ALVARADO A., MATA R., CHINCHILLA M. 2014. Arcillas identificadas en suelos de Costa Rica a nivel generalizado durante el período 1931-2014: I. Historia, metodología de análisis y mineralogía de arcillas en suelos derivados de cenizas volcánicas. Agronomía Costarricense 38(1): 75-106.

ALVES M.E., LAVORENTI A. 2004. Clay mineralogy effects on sodium fluorite $\mathrm{pH}$ on non-allophanic tropical soils. Australian Journal of Soil Research 42:865-874.

ANDERSON MS, BYERS HG. 1931. Character of the colloidal materials in the profiles of major soil groups of the United States. U.S. Dept. Agr. Tech. Bull. 228 p.
ARAYA J.M. 1979. Caracterización química y física y clasificación de 10 perfiles de suelos en Pérez Zeledón. Tesis de Ing. Agr., Escuela de Fitotecnia, Universidad de Costa Rica. San José, Costa Rica. $123 \mathrm{p}$.

ARIAS F., MATA R., ALVARADO A., SERRANO E., LAGUNA J. 2010a. Caracterización química y clasificación taxonómica de algunos suelos cultivados con banano en las llanuras aluviales del Caribe de Costa Rica. Agronomía Costarricense 34(2):177-195.

ARIAS F., MATA R., ALVARADO A., SERRANO E., LAGUNA J. 2010b. Mineralogía de la fracción arcilla de algunos suelos cultivados con banano en las llanuras aluviales del Caribe de Costa Rica. Agronomía Costarricense 34(2):197-222.

BERRANGÉ J.P., MATHERS S.J., MORALES N., ALVARADO F. 1990. The non-metallic industrial minerals and rocks of Costa Rica. Proyecto AngloCostarricense de Minerales Industriales (PACOMI). Direc. Geol. Min. Hidroc., British Geol. Surv./ RECOPE. Informe Interno. San José, Costa Rica. $181 \mathrm{p}$.

BERTOLANI M., LOSCHI-GHITTONI A.G. 1986. Clay minerals from the Central Valley of Costa Rica and their possible ceramic uses. Applied Clay Science 1:239-254.

BESOAIN E. 1985. Mineralogía de arcillas de suelos. San José, CR, IICA. 1216 p. Serie de Libros y Materiales Educativos; No. 60. 1205 p.

BOLEY J.D., DREW A.P., ANDRUS R.E. 2009. Effects of active pasture, teak (Tectona grandis) and mixed native plantations on soil chemistry in Costa Rica. Forest Ecology and Management 257:2254-2261.

BROWN G., BRINDLEY G.W. 1980. X-ray diffraction procedures for clay mineral identification. In. Brindley, GW y Brown, G. (ed.) Crystal structures of clay minerals and their X-ray identification. Mineral Society Monograph No. 5. London. pp. 305-356.

CASTILLO R. 1997. Recursos minerales de Costa Rica: génesis, distribución y potencial. Editorial de la Universidad de Costa Rica. San José, Costa Rica. $221 \mathrm{p}$.

CHARPANTIER D., BUATIER M.D., JACQUOT E., GAUDIN A., WHEAT C.G. 2011. Conditions and mechanism for the formation of iron-rich montmorillonite in deep sea sediments (Costa Rica margin): coupling high resolution mineralogical characterization and geochemical modeling. Gechemica et Cosmochemica Acta 75:1397-1410.

CORTÉS J. 1981. The coral reef at Cahuita, Costa Rica, a reef under stress. MS thesis. Hamilton, Ontario, Canada, McMaster University. 176 p.

CUBERO D. 2002. Estudio semidetallado de suelos y clasificación de suelos para la Cuenca del río Savegre. 
MAG/ Departamento de Suelos y Evaluación de Tierras. San José, Costa Rica. 61 p.

DENGO G. 1962. Estudio Geológico de la Región de Guanacaste. Ministerio de Obras Públicas e Instituto Geográfico de Costa Rica, San José, Costa Rica. $122 \mathrm{p}$.

DRIESE S.G., ORVIS K.H., HORN S.P., LI Z., JENNINGS D.S. 2007. Paleosol evidence for Quaternary uplift and the climate and ecosystem changes in the Cordillera de Talamanca, Costa Rica. Paleogeography, Paleoclimatology, Paleoecology 248:1-23.

DROSDOFF M., PEARSON R.W. 1951. Soil and leaf analysis in relation to abaca production in Central America. IICA. Abaca Research Report No. 5.25 p.

FISHER G.B., RYAN P.C. 2006. The smectite-to-disordered kaolinite transition in a tropical soil chronosequence, Pacific Coast, Costa Rica. Clays and Clay Minerals 5:571-586.

FISKEL J.G.A., ILEY J.R. 1961. Report on the clay fraction of Costa Rican soils. University of Florida. Mimeo Report. USA. 5 p.

GAUDIN R.M., BUATIER M.D., BEAUFORD D., PETIT D., GRAUBY O., DECAREAU A. 2005. Characterization and origin of $\mathrm{Fe}^{+3}$-montmorillonite in deep water calcareous sediments (Pacific ocean, Costa Rica margin). Clay and Clay Minerals 53:452465.

GÓMEZ O., CHINCHILLA M. 2005. Estudio taxonómico y mineralógico de los suelos de la cuenca del río Térraba a escala 1:50.000, provincias de Puntarenas y San José. MAG/ICE. San José, Costa Rica. 226 p.

HAMMARLUND L., PIÑONES J. 2009. Arsenic in geothermal waters of Costa Rica. A minor field study. Master Thesis. Land and Water Resources Engineering at KTH. Stockholm, Sweden. 38 p.

HARMAND J.M., ÁVILA H., OLIVER R., SINT-ANDRÉ L., DAMBRINE E. 2010. The impact of kaolinite and oxi-hydroxides on nitrate adsorption in deep layers of a Costarrican Acrisol under coffee cultivation. Geoderma 158:216-224.

HOLDRIDGE L.R., GRENKE W.C., HATHEWAY W.H., LIANG T., TOSI J.A. 1971. Forest environments in tropical life zones: a pilot study. Pergamon Press. Great Britain. 741 p.

HYMAN G.G. 1997. Sediment transfer in the Río Pacuare watershed and neighboring basins of Costa Rica. Tesis Doctorado. The University of Tennessee, Knoxville, TN (USA). 172 p.

JONGMANS A.G., van OORT E., JAUNET A., van DOESBURG J.D. 1994. Inheritance of 2:1 phyllosilicates in Costa Rican Andisols. Soil Science Society of America Journal 58:494-501.

JOUSSEIN E., PETIT S., CHURCHMAN J., THENG B., RIGHI D., DELVAUX B. 2005. Halloysite clay minerals - a review. Clay Minerals 40:383-426.
KAUTZ C.Q., RYAN P.C. 2003. The $10 \AA$ to $7 \AA$ halloysite transition in a tropical soil sequence, Costa Rica. Clays and Clay Minerals 51:252-263.

KESEL R.H., SPICER B.E. 1985. Geomorphologic relationships and ages of soils on alluvial fans in the Rio General Valley. Costa Rica. Catena 12:149-166.

KLEBER M., SCHWENDENMANN L., VELDKAM E., RÖFFNER J., JAHN R. 2007. Halloysite versus gibbsite: silicon cycling as a pedogenetic process in two lowland neotropical rain forest soils of La Selva, Costa Rica. Geoderma 138:1-11.

KREZDORN A.H., ROBERTSON W.K., REUSS L.A. 1967. Potential for citrus production in Costa Rica' Atlantic Zone. University of Florida/AID Mimeo Report. 31 p.

KRISHNASWAMY J., RITCHER D.D. 2002. Properties of advanced weathering-stage soils in tropical forest and pastures. Soil Science Society of American Journal 66:244-253.

LAGUNA J.E. 1985. Mineralogía de las arcillas de las rocas volcánicas alteradas de la parte sur-central de la Cordillera de Tilarán, Costa Rica. Ciencia y Tecnología (CR) 9(1-2):11-27.

LÓPEZ C.A. 1963. Identificación y clasificación de los minerales de arcilla presentes en nueve suelos de Costa Rica. Tesis Ing. Agr., Facultad de Agronomía, Universidad de Costa Rica. San José, Costa Rica. $56 \mathrm{p}$.

MACIAS M. 1969. Propiedades morfológicas, físicas, químicas y clasificación de ocho "Latosoles" de Costa Rica. Tesis Mg. Sc. IICA. Turrialba, Costa Rica. 193 p.

MATA R. 1982. Variaciones pedogenéticas en tres secuencias topográficas del Pacífico seco de Costa Rica. Tesis M.Sc. Turrialba, Costa Rica, CATIE. 147 p.

MATA R., RAMIREZ J.E. 1999. Estudio de caracterización de suelos y su relación con el manejo del cultivo del café en la provincia de Heredia. ICAFE. San José, Costa Rica. 92 p.

MATA R., MOLINA E., ALVARADO A. 1996. Principales Vertisoles de Costa Rica. In F. Bertsch, W. Badilla y E. Bornemisza (eds.). Memorias 10 Congreso Nacional Agronómico y de Recursos Naturales. San José, Costa Rica. EUNED/EUNA. Vol. 3. p. 39.

MATHERS S.J., MADRIGAL J.E., ALVARADO F. 1991. Results of an initial exploration programme for bentonitic clays in Costa Rica. Proyecto AngloCostarricense de Minerales Industriales (PACONI). BGS Technical Report WC / 90 / 36. 24 p.

MIZOTA C., van REEUWIJK L.P. 1989. Clay mineralogy and chemistry of soils formed in volcanic material in diverse climatic regions. Int. Soil Reference and Information Centre, Wageningen, the Netherlands. Soil Monograph 2. 185 p. 
MORA R. 2007. Suelos expansivos de la ciudad de Limón, Costa Rica: Caso urbanización Quiribrí. Proyecto Fundevi 0960. Servicios especializados de Laboratorio de Suelos y Rocas (SELSYR) FUNDEVI, Universidad de Costa Rica. 28 p.

MOTAVAlLi P., PALM C., ELLIOT E., FREY S., SMITHSON P. 1995. Nitrogen mineralization in humid tropical forest soils: mineralogy, texture, and measured nitrogen fractions. Soil Science Society America Journal 59:1168-1175.

NAKAMURA M.T., SHERMAN G.D. 1965. The genesis of halloysite and gibbsite from mugearite on the island of Mani. Tech Bull. Hawaii Agric. Exper. Station $62.35 \mathrm{p}$.

NIEUWENHUYSE A. 1996. Soils, geology, and soil-related sustainability aspects of the perhumid tropical Limón basin, Costa Rica. Serie Técnica. Informe Técnico (CATIE) no 272. CATIE, Turrialba. Costa Rica. $85 \mathrm{p}$.

NIEUWENHUYSE A., van BREEMEN N. 1997. Quantitative aspects of weathering and neoformation in selected Costa Rican volcanic soils. Soil Science Society of America Journal 61(5):1450-1458.

NIEUWENHUYSE A., KROONENBERG S.B. 1994. Volcanic origin of Holocene beach ridges along the Caribbean coast of Costa Rica. Marine Geology 120:13-26.

NIEUWENHUYSE A., JONGMANS A.G., van BREMEN N. 1994. Mineralogy of a Holocene chronosequence on andesitic beach sediments in Costa Rica. Soil Science Society of America Journal 58:485-494.

NIEUWENHUYSE A., VERBIRG P.S.J., JONGMANS A.G. 2000. Mineralogy of a chronosequence on andesitic lava in humid Costa Rica. Geoderma 98:61-82.

NÚÑEZ J. 1986. Estudio semidetallado de suelos en el área sur de la cuenca del río Tuís. Tesis Mag. Sc. Programa de Posgrado Convenio Universidad de Costa Rica / CATIE, Turrialba, Costa Rica. 310 p.

ORTÍZ R.A., COLLINS M.E. 1992. Clay mineralogy of alluvial soils from the Pacific Coast of Costa Rica. Agronomy Abstracts. pp. 361.

PACHECO R. 1990. El manejo de suelos de baja fertilidad con énfasis en los Ultisoles del Valle del General. 1 Seminario sobre el Manejo de Suelos Tropicales: Posibilidades y limitaciones ecológicas, GOETHEPRODAF(GTZ)-UNED (PEA), San José, Costa Rica. 16 p.

PELT E., CHABEAUX F., INNOCENT C., NAVARRE A.K., SAK P.B., BRANTLEY S.L. 2008. Uraniumthorium chronometry of weathering rinds: rock alteration rate and paleo-isotopic record of weathering fluids. Earth and Planetary Science Letters 276:98-105.

PORTA J., LOPEZ-ACEVEDO M., ROQUERO C. 1994. Edafología para la agricultura y el medio ambiente. Ediciones Mundi-Prensa. España. 807 p.
QUANTIN P., BALESDENT J., BOULEAU A., DELAUNE M., FELLER C. 1991. Premier stades d'alteration de ponces volcaniques en climat tropical humide. (Montagne Pelee, Martinique). Geoderma 50:125148.

ROCHELlE C.A., MILODOWSKI A.E., SAVAGE D., CORELLA M. 1989. Secondary mineral growth in fractures in the Miravalles geothermal system, Costa Rica. Geothermics 18(1/2):279-286.

SÁENZ A. 1983. Lateritas y suelos lateríticos de Costa Rica. Facultad de Agronomía, Escuela de Fitotecnia, Universidad de Costa Rica. San José, Costa Rica. $19 \mathrm{p}$.

SAK P.B., FISHER G.M., GARDNER T.W., MURPHY K., BRANTLEY S.L. 2004b. Rates of weathering ring formation on Costa Rica basalt. Geochimica and Cosmochimica Acta 68(7):1453-1472.

SALAZAR C. 2012. Caracterización mineralógica de arcillas de algunos suelos en la cuenca del río Savegre, Costa Rica. Proyecto de tesis. Maestría en Ciencias Agrícolas y Recursos Naturales con Énfasis en Suelos. Sistema de Estudios de Posgrado, Universidad de Costa Rica. San José, Costa Rica. $29 \mathrm{p}$.

SÁNCHEZ E.S. 1994. Análisis difractométrico. Laboratorio Petrología, Área de Geología, Dpto. Recurso Geotérmico, Instituto Costarricense de Electricidad. San José, Costa Rica. 2 p.

SCHAETZL R., ANDERSON S. 2005. Soils: genesis and geomorphology. Cambridge University Press, United Kingdom. $821 \mathrm{p}$.

SCHEUCHER L.E.A., VORTISCH W., LAGUNA J. 2008. Geological and mineralogical investigations of the lithologies and their weathering products in a study area south-west of the field station "La Gamba", Golfo Dulce, Costa Rica. In A WEISSENHOFER, W HUBER, V MAYER. S PAMPERI, A WEBER, G AUBRECHT (eds). Natural history of the Golfo Dulce region, Costa Rica. Stapfia 88. pp 31-45.

SCHWARTZ R.G. 1998. Reactive transport of tracers in a fines textured Ultisol. Thesis Ph.D. Texas A\&M University, Graduate School and Soil Science, Texas, USA. 183 p.

SOIL SURVEY STAFF. 2006. Keys to soil taxonomy.9th.ed., Washington, USA. Natural Resources Department of Agriculture. United States, Department of Agriculture. $321 \mathrm{p}$.

SOTO J.A. 1998. Formas de fósforo y su liberación en Andisoles de la región central oriental de Costa Rica. Tesis Doctorado, Universidad de Córdoba, España. $155 \mathrm{p}$.

SPINELLI G.A., UNDERWOOD M.B. 2004. Character of sediments entering the Costa Rica subduction zone: implications for partitioning of water along the plate interface. The Island Arc 13:432-451. 
SPOSITO G. 1989. The chemistry of soils. Oxford University Press, New York, USA. 342 p.

STOTZKY G., MARTÍN R.T. 1963. Soil mineralogy in relation to spread of Fusarium wilt of banana in Central America. Plant and Soil 16(3): 317-337.

SUDO T., SHIMODA S. 1978. Developments in sedimentology, 26: Clays and Clay Minerals of Japan. Elsevier. Tokio. 326 p.

USDA-SCS. 2012. Soil survey laboratory primary characterization, data of some Costa Rican soils. Internal Report. Lincoln, Nebraska. sp.

VAN DOOREMOLEN W.A., WIELEMAKER W.G., van REEMEN N., MEIJER E.M., van REEWIJK L.P. 1990. Chemistry and mineralogy of Andosols of various age in a soil chronosecuence of andesitic lahars in Costa Rica. 2nd. International Symposium, Geochemistry of the earth's surface and of mineral formation. Aix en Provence, France. Chemical Geology. Journal of the European Association for Geochemistry 84(1/4):39-141.

VARGAS O., TORRES J.A. 1958. Estudio preliminar de suelos de la región occidental de la Meseta Central. San José, Ministerio de Agricultura e Industrias. Boletín Técnico $\mathrm{N}^{\circ} 22.64 \mathrm{p}$.

VÁSQUEZ A. 1978a. Estudio detallado de suelos y clasificación de tierras para riego: evaluación de los recursos de tierras y aguas con fines de riego. Tomo 1. Central Azucarera Tempisque S.A., Liberia, Guanacaste. 142 p.

VÁSQUEZ A. 1978b. Cuenca Baja del río Tempisque. Estudio semidetallado de suelos, área de la I etapa. Dirección de Riego y Drenaje, Departamento de Suelos, Ministerio de Agricultura y Ganadería. San José, Costa Rica. 159 p.
WEISSENHOFER A., HUBER W. 2008. The climate of the Esquinas rainforest. In. A WEISSENHOFER, W HUBER, V MAYER, S PAMPERL, A WEBER, G AUBRECHT. (eds.). 2008. Natural and cultural history of the Golfo Dulce region, Costa Rica. Stapfia 88. pp. 59-62.

WILDING L.P., PUENTES R. (eds.). 1988. Vertisols: their distribution, properties, classification and management. Soil Management and Support Services. Technical Monograph No. 18. Texas A\&M University Printing Center. TX, USA. 193 p.

WILCKE W., KRETZCHMAR S., BUNDT M., ZECH W. 1999. Metal concentrations in aggregate interiors, exteriors, whole aggregates, and bulk of Costa Rican soils. Soil Science Society of America Journal 63:1244-1249.

WILCKE W., KRETZSCHMAR S., BUNDT M., SOBORÍO G., ZECH W. 2000. Depth distribution of aluminum and heavy metals in soils of Costa Rica coffee cultivation areas. Journal of Plant Nutrition and Soil Science 163:499-502.

WILSON M.J. 1999. The origin and formation of clay minerals in soils: past, present and future perspectives. Clay Minerals 34:7-25

WINOWIECKI L. 2008. Soil biochemical patterns in the Talamanca foothills, Costa Rica: local soil knowledge and implications for agroecosystems. $\mathrm{Ph}$. D. Dissertation, Ohio University/Centro Agronómico Tropical de Investigación y Enseñanza. USA. 172 p.

WINTERS A.F. 1997. Soils on the Pleistocene Ignimbrite Bagaces Formation, Guanacaste, Costa Rica: a report on the results of two thesis. Department of Soil Science and Geology. Agricultural University of Wageningen, The Netherlands. 68 p. (Apéndices). 
